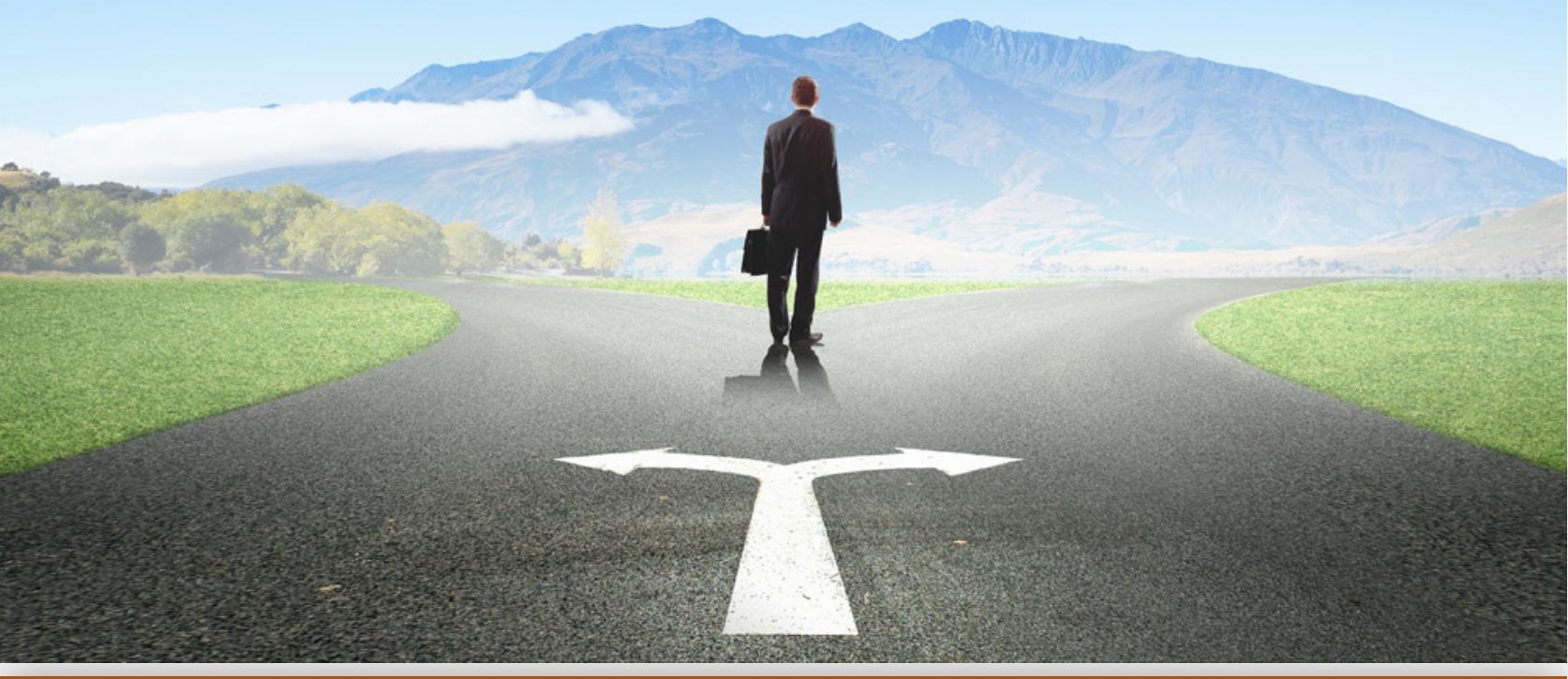

Adriana Wiegerová

\title{
THE CAREERS OF YOUNG CZECH UNIVERSITY TEACHERS
}

\section{IN THE FIELD OF PEDAGOGY}



Tomas Bata University in Zlín 



\section{Adriana Wiegerová}

\section{THE CAREERS OF YOUNG}

\section{CZECH UNIVERSITY TEACHERS}

IN THE FIELD OF PEDAGOGY

Tomas Bata University in Zlín 
KATALOGIZACE V KNIZE - NÁRODNÍ KNIHOVNA ČR

Wiegerová, Adriana

The careers of young Czech university teachers: in the field of pedagogy / Adriana Wiegerová.

-- 1st edition. -- In Zlín : Tomas Bata University, 2021. -- 1 online zdroj. -- (Pedagogy)

Obsahuje bibliografii a rejstř́iky

ISBN 978-80-7454-988-5 (online ; pdf)

* 378.011.3-051*005.966*37.012*(437.3)*(048.8)

- vysokoškolští učitelé -- Česko

- rozvoj kariéry -- Česko

- pedagogický výzkum -- Česko

- monografie

378 - Vysoké školy [22]

(C) Adriana Wiegerová, 2021

(C) Tomas Bata University in Zlín, 2021

Faculty of Humanities/Pedagogy series

ISBN 978-80-7454-988-5 
For you...

The publication was approved by the Scientific Board of the Pedagogy Series in Tomas Bata University Press

on October 28, 2016 



\section{CONTENTS}

PREFACE

INTRODUCTION

A NOTE ON UNIVERSITIES IN THE CZECH REPUBLIC

1/ THE PROFESSIONAL CAREER AND ITS DETERMINANTS

1.1 Personal Determinants of a Professional Career

1.2 Planning and Managing Professional Careers

2/ THE PURPOSE AND ACTUALISATION OF THE STUDY

2.1 Research Methodology

2.1.1 Aims of the Study

2.1.2 The Study Participants 28

2.1.2.1 Men in the Study 29

2.1.2.2 Women in the Study 31

2.1.3 Research Method 34

2.1.4 Performing the Interview 34

2.1.5 Transcription 35

2.1.6 Data Analysis 36 
3.1 Why did I Enrol in the Doctoral Programme?

3.1.1 A University's Motivation for Encouraging Enrolment in a Doctoral Programme

3.1.2 Family as a Source of Motivation for Enrolment in a Doctoral Programme

3.1.3 Conviction to Become a Student in a Doctoral Programme

3.2 I Am a Doctoral Student

3.2.1 Acquiring the Doctoral Student's Social Roles

3.2.1.1 The Student's Role 50

3.2.1.2 The Teacher's Role 52

3.2.1.3 The Researcher's Role 55

3.2.1.4 The University Employee's Role 58

3.2.1.5 The University Administrator's Role 60

3.2.2 A Key Person as a Researcher's Model 61

3.2.3 Integration into the Professional Community 63

3.3 Specifying the Dissertation Topic 65

3.4 Conditions for the Study 68

3.4.1 The Supervisor 68

3.4.2 University Rules 71

$\begin{array}{ll}3.5 \text { Finalising the Dissertation } & 73\end{array}$

$\begin{array}{ll}\text { 3.5.1 Family Support } & 73\end{array}$

3.5.2 Support by the Supervisor and Colleagues $\quad 74$

3.5.3 A PhD as a Job Prerequisite $\quad 75$

4/ AFTER COMPLETION OF DOCTORAL STUDIES

4.1 Occupational Adaptation $\quad 82$

4.2 Social Identification $\quad 85$

4.3 Adaptation to the University Culture $\quad 89$ 
5/ CAREER PLANS OF PhD GRADUATES

5.1 The Goal - Associate Professorship 96

5.2 A teacher and a Researcher 99

6/ CAREERS OF YOUNG UNIVERSITY TEACHERS IN THE CZECH REPUBLIC $\quad 105$

6.1 Career Decisions Made by University Teachers 105

6.2 Trajectories in the Occupational and Professional Careers of University Teachers

CONCLUSION

REFERENCES

FIGURES AND TABLES

AUTHOR INDEX 



\section{PREFACE}

My first encounter with doctoral studies was many years ago. Back in the last century (how oddly it sounds), I was a doctoral student in pedagogy in the Faculty of Arts at Comenius University in Bratislava. In the 1990s, doctoral students in the Czech Republic and Slovakia studied under conditions much different from today's. Research methodology books were scarce, professional journals were poor, supervisors were inexperienced in modern research methods, and collegial contacts across the country were infrequent. Simply, there were many obstacles to earning a PhD. Also, the career development opportunities were much narrower and more straightforward when compared to today's career paths of young university teachers.

Recalling these circumstances motivated me to investigate the study and professional careers of a group of young men and woman who completed their doctoral programmes and recently started their teaching and research careers at Czech universities. The decision was made four years ago, and the result of my investigation is this book. I was determined that the book would be based on authentic descriptions of study participants' experiences, so the book is based on in-depth interviews with them. The next step - to find consistency across the data in order to make concise conclusions - proved challenging. It soon became clear that to make sense of the messy and complex topic was a laborious process.

When the manuscript approached its final form, the decision was made to publish the book in English, in order to make it more widely accessible. Colleagues abroad will view the academia and professional realities in the Czech Republic through their own lenses, and can compare it with their own situations.

I confess that the manuscript was not easy to write. I had and continue to have huge respect and admiration for the study participants and their valuable opinions. I am sure that even though their identities were anonymized, if they happen to 
read this book they will identify themselves easily and will view their study and professional careers in comparison with those of other young individuals described in the book. This, I hope, will result not only in a nostalgic recall of events but also in professional self-reflection about the individual phases of the careers and their determinants.

I want to express my appreciation to the manuscript reviewers, Jiří Mareš, Eliška Walterová and Beata Kosová, who are, in my opinion, leading thinkers and researchers in the field. I am much indebted to their suggestions and comments, which certainly improved the final product.

During the writing and editing phases, I closely collaborated with the book's scientific editor, Peter Gavora. I am grateful for both his support and patience. Many important suggestions were provided by Gregory Jason Bell, who not only proofread the manuscript but also shaped the English into a more appropriate monograph style.

Finally, my thanks belong to the Tomas Bata University Press for typesetting and printing this book. I express my appreciation to my workplace, the Faculty of Humanities at Tomas Bata University, which subsidised the publishing.

This work is dedicated to young university teachers who have just started their professional lives in academia. They will find accounts concerning socialisation in academia, teaching experiences and research endeavours, which I hope will attract their attention, generate sympathy, and may inspire. 


\section{INTRODUCTION}

In recent years, the professional community in Czech universities has been discussing the issue of the quality of doctoral programmes in pedagogy and related fields (Neusar, et al., 2012; Wiegerová, et al., 2013). Associated with these discussions has been the topic of improving conditions for the professional development of $\mathrm{PhD}$ graduates at universities and research institutions (Mareš, 2013b; Šed'ová et al., 2016). These studies provided a picture of how intriguing and demanding doctoral studies are as viewed by doctoral students and graduates.

Mareš (2013b) analysed data on PhD graduates between 1999 through 2011 in pedagogy. On average there were 42 students who annually graduated in pedagogy doctoral programmes offered at faculties in the Czech Republic. He then wondered what became of the graduates, why the research groups in the country were not expanding in number and size, and why the quality of Czech educational research has not improved.

One of the reasons is that the graduates were not offered jobs at a faculty, but there are other reasons as well. These young individuals were not adequately vocationally guided during studies and were not sufficiently professionally supported after graduation. The post-graduation phase in the career of young individuals seems to be as important as the pre-graduation phase. Yet, no adequate system of guidance and no meaningful developmental programmes were offered to them.

In light of these problems, two tasks emerge: to create new jobs for young doctoral graduates in academia and to support their professional competencies. One of the solutions is to offer them systematic and continuous professional development programmes.

To help complete these tasks, this book describes the careers of ten young academics employed at universities in the Czech Republic. Their stories are based on in-depth interviews that took place and were recorded in an academic setting. 
They do not illustrate exemplary paths to and through the academic career. Rather, they show how people with different personalities, priorities and home backgrounds have negotiated the academic job career opportunities with a certain degree of success. The interviews revealed the inner world of young individuals who belong to the same young generation and who had to make key decisions in every stage of their academic careers, supported by their resilience, courage and stamina.

Each young individual must decide what career path to follow after graduation. One of the options is to find a job at a university. Personal decisions are key elements in an individual's professional career. They affect the personal constructs, while the previously-existing personal constructs influence subsequent personal decisions. Personal decisions, in turn, are determined by career possibilities and opportunities. The general goal is to reach congruence among career possibilities, opportunities, and sufficient personal satisfaction.

Personal decisions are important internal factors in making use of career choices. The availability of adequate jobs is an external factor that determines career choices. A young individual may not apply for a job in academia because they do not consider teaching and research as a primary interest. But even though they want to be employed at a university, there may be no available jobs. The young individual also may postpone the decision to become employed in academia by several years. If the desire is strong, the young individual's goals will be directed to meet the personal decisions to obtain a job at a university.

This book contains six chapters. In Chapter 1, theories that constitute the book's axis are presented. In the foreground are determinants of a professional career as inspired by theories of Eccles and Kelly. Chapter 2 describes the methodology of the investigation. Details are provided on research aims, study participants, the data gathering method and processing. Chapter 3 describes the factors that determine the career decisions of a young individual: family, friends, and the workplace. Chapters 4-6 describe the professional trajectories of those young individuals who decided to become employed in academia. The book identifies the important milestones in their careers as well as obstacles they had to overcome in adapting to the university environment. During the adaptation processes, they modified their personal constructs, professional concepts and values. The chapters reveal the sequence of these changes from the start of their doctoral studies to the present time.

To make the book more accessible for an international audience, it was translated into English. In order to make some facts about universities in the Czech Republic understandable, a brief chapter describing the Czech university was included, detailing qualification requirements for teachers, ranks of the staff, duration and 
forms of study, student responsibilities, etc. The reader will come across many other details about Czech universities within the text and will infer the meanings from the contexts.

While understanding the Czech university setting may cause problems for international readers, some English terminology may confuse Czech professionals. For instance, I used the term "career", the key word in this book, in a much broader sense than the equivalent Czech term of "kariéra". In my usage, a career includes an individual's developmental sequences not only in the vocational domain, but also in the family and community.

The book is based on interviews with a group of young Czech university teachers. Their accounts reflect the specific situations and circumstances of their academic and professional lives. Therefore, the book's conclusions cannot be safely generalized to other environments and professional and study conditions. But, I believe that the data and the conclusions may inspire the generation of new research questions for following studies concerning the careers of young university teachers. 


\section{A Note on Universities in the Czech Republic}

To clarify the context and terminology for readers outside of the Czech Republic, a brief explanation is provided here.

The employees that are hired by universities in the Czech Republic will be referred to collectively in this book as university teachers (akademičtí pracovníci). In addition to teaching courses, they are responsible for conducting research, publishing and administrative tasks. The minimum qualification required for the position is a PhD in the particular field. The usual employment contract is for a certain period of time; permanent contracts are less frequent and are usually signed with senior university teachers.

Traditionally, the ranks of university teachers are in ascending order: lecturer (lektor), instructor (asistent), assistant lecturer (odborný asistent), associate professor (docent) and professor (profesor). In 2016, the University Law introduced the rank of special professor (mimořádný professor). Administrative ranks are vice-dean (proděkan), dean (děkan), vice-rector (prorektor) and rector (rektor).

The university usually offers three-level programmes for obtaining bachelor's, master's and doctoral degrees. Doctoral programmes are offered either full-time (denní forma) or part time (kombinovaná forma). A PhD candidate is referred to as a doctoral student (doktorand) even though their major responsibility is to carry out independent research and be socialized into the research community. The doctoral student is supported by an academic supervisor (školitel).

The doctoral programmes also have a required coursework component. The full-time student is offered a scholarship provided by the Ministry of Education. In addition to conducting research and doing coursework, the full-time doctoral student usually has administrative and teaching responsibilities. The doctoral programme is completed by a successful dissertation defence that is supposed to make a significant contribution to the field. A formal oral comprehensive examination precedes the dissertation defence. The full-time programme typically takes four years, while the part-time programme is usually longer.

Postdoctor positions (postdoktorand) are offered for 1-3 year periods of time and are infrequent in the humanities. 


\section{THE PROFESSIONAL CAREER AND ITS DETERMINANTS}

There are two basic approaches to studying careers. Sociologists have been interested almost exclusively in career choice and development on the vertical (prestige) dimension - how one advances up the socioeconomic ladder. The individual's motivation and goals have been restricted to educational attainment and the prestige of occupations. On the other hand, psychologists have been studying careers with the emphasis on the personality characteristics that predispose a certain type of career. They have concentrated on studying a person's interests, values, self-concept and personality type as determinants of occupational choices (Kirkpatrick Johnson \& Mortimer, 2002). The psychological, rather than sociological, approach to the study of careers will prevail in this book.

A career is defined as a developmental sequence that takes place during a life span. Its course can be either ascending or descending, comprised of growth, stagnation or decline. A career is frequently conceptualized as an individual's professional and occupational trajectories. This is, however, a narrow view because, in addition to these trajectories, an individual pursues also a personal career.

A personal career is a developmental sequence in one's private sphere. An individual's personal values are shaped in interactions with people and institutions. The most important influential institution is family. If a goal of a personal career is a family's prosperity, then the person makes life decisions to achieve this goal. The personal goals then are targeted on building and stabilizing the family, in particular, its economic, social and biological components.

Due to historical traditions, the family has a more important personal value for females than for males. In the past, careers of women were focused on forming a favourable family environment for men, who were employed and earned money for the family (Heitlingerová \& Trnková, 1998). Nowadays, the situation has changed: 
most women are employed, and their family roles as well as their self-concepts have been adjusted accordingly.

A professional career is a developmental sequence in an individual's profession. It should be distinguished from the occupational career, as it is a broader concept. The professional career is an on-going process of developing experience in a profession, and it may evolve in several organizations in which an individual is employed during their lifetime. This concept also emphasizes the peculiarity of a profession and its autonomy, as manifested by a special mandate, which has its own ethical codes and norms. These are the bases of the functioning of the professional community. A professional career is linked to experiences. It is a route that makes it possible to understand one's behaviour and actions in the professional life.

Between genders there exist large differences in valuing professional careers. As Weisgram, Bigler and Liben (2010) proved, some professions are traditionally characterized as feminine and others as masculine. Their respondents labelled occupations with regards to money, power, family, and altruism. Results revealed gender differences in occupational values and interests. Furthermore, participants' values predicated their own interests in masculine and feminine professions. Importantly, this rating was proved across all age groups (adults, adolescents and children).

An occupational career is a developmental sequence in one's occupations. The selection criterion of a particular occupation is the salary or other benefits, such as power and authority, as well as time available to spend with family and to devote to free time activities. The occupational career comprises not only an occupational position; it also includes "work ownership", employment and its execution. An occupation is regulated by workplace rules as well as by general occupational norms, such as the labour code.

An occupational career is a sequence of jobs that create an opportunity for the development of self, institution and society. Also with this aspect there are gender differences. Weisgram, Bigler and Liben (2010) report that their respondents attributed the highest scores on income to a doctor, a professional athlete, a lawyer, a dentist, and a supreme court judge. Approximately identical ratings were attributed to a scientist, a computer engineer, a chemist, and an airline pilot. A scientist was rated in the middle of the occupation hierarchy list, and it was qualified as a masculine occupation. Concerning altruism, the highest rankings were attributed to a doctor and a fireman, followed by a dentist. In feminine occupations, salary ratings were lower. The top salary ranking was attributed to a nurse, a jewellery maker, and a hair stylist. The same ranking was attributed to an elementary school teacher, a librarian and a social worker. In altruism, the highest 
ranking was attributed to a teacher and nurse, followed by a social worker. Among feminine occupations, a teacher was the highest ranked in power. A scientist did not appear in female occupation rankings. From this it can be inferred that the occupational career of a scientist is generally associated with men.

Basically the same conclusion was reported in a large-scale investigation of 350,000 respondents from sixty-six countries. Science was bound to masculinity in the great majority of nations - surprisingly, also in societies with self-proclaimed gender equality. The proportion of women participating in research jobs was smaller than of men (Miller, 2015). No wonder there exists the stereotype that science is a man's domain.

Similarly, it can be inferred that the teaching profession is predominantly feminine. However, it is not so with university teachers. Chapters 3-5 describe the professional as well as personal lives of both male and female university teachers.

\section{1}

\section{Personal Determinants of a Professional Career}

A professional career is influenced by values and personal constructs, which, in turn, shape one's self-concept. Values are relatively stable personal qualities that considerably affect one's attitudes towards people, situations and objects. Personal values serve as standards for assessing one's own behaviour and the behaviour of others.

This chapter uses concepts and categories that were drawn from the theory of American educational psychologist J. S. Eccles (1994). She connected value preferences with career aspiration goals and determinants of professional careers. Eccles and her team devoted more than fifteen years to the investigation of motivational and social factors that affect both short-term and long-term attainment goals and behaviours. These factors were career aspirations, vocational and avocational choices, persistence in difficult tasks and the spreading of efforts across achievement behaviours. They developed a complex theoretical model based on the achievement needs of an individual, based on two types of beliefs:

a) An individual's expectation of success.

b) Values an individual attributes to available choices.

In this model, Eccles conceptualized attainment value in several ways: as career importance and usefulness, career interest, and the price for the choice of a career in comparison with other careers. An individual's attainment value is a significant 
element in this model because it influences both educational and career options and attainment expectations. This model predicts that career choice is determined by an individual's value attributed to career attainment options.

This model shows the importance of

a) An individual's values for setting long-term goals.

b) An individual's interests.

c) The value of attainment that is consistent with an individual's self-image.

d) The value of an individual's engagement in activity or vocation.

Eccles claims that attainment value is defined through needs and personal values. During their development, individuals form an image of who they are and what they would like to be.

This image is made up of these components:

- conceptions of one's personality and capabilities,

- long range goals and plans,

- schema regarding roles of men and women in one's culture,

- instrumental and final values,

- motivational sets,

- ideal images of what one should be like,

- social scripts of behaviour in a variety of life situations.

These components are parts of an individual's self-image and are important in definition of self. They affect a value system used in attaining one's professional career.

An individual has a personal value system, which plays a key role in determining attitudes towards life, self, and others. An individual creates a personal construct according to personal values and convictions, what one wants to do and which direction to take.

Personal constructs are "minitheories" used to understand one's experiences. The concept of a personal construct was originally developed by G. Kelly (1970; 1977, cited by Fournier \& Paine, 1994) to describe how individuals make sense of the world. For Kelly, people behave like scientists: they form hypotheses about events and test them. If a particular construct applies to a particular event, it will be accepted and then used to predict other events. This implies a continual renewal of constructs. New experiences or an entry into a new occupational culture are good examples of catalysts of construct revision (Fransella \& Dalton, 1990).

The concept can be explained with a workplace example: when an employee starts a job, the employee has an initial personal construct. At the workplace, 
the employee enters into contacts with other employees, listens to their conversations, observes their behaviours, and compares this with their personal construct. If adequate, the knowledge will be integrated into a personal construct and will be used to predict other workplace events. Based on the personal construct, the employee decides how to shape the professional career.

Kelly (1970; 1977, cited by Fournier \& Paine, 1994) describes the experience as a cycle containing five phases, which starts in the actual construct system and ends in its revision.

These phases are as follows:

- anticipation,

- investment,

- encounter,

- confirmation or disconfirmation,

- constructive revision.

Three of these phases are of particular importance in understanding changes in the transition from the anticipatory phase to the occupational phase: anticipation (change of the channel of the actual system), disconfirmation, and constructive by extension. The channel can be described as a transition from one professional phase to another.

Anticipation can be explained through an example of a graduate who enters an occupation with a construct system, which has been developed from past experiences. The graduate has a certain view of self and others, has an image of desired work, and has certain values. In the personal construct theory, the current constructs are crucial in guiding the constructive revision that graduates might undertake. This is consistent with the findings of studies on subjects who entered an organizational life (e.g., Arnold, 1990; Arnold \& Nicholson, 1991; Honess, 1989).

Disconfirmation. If there exists a discrepancy between a graduate's anticipation of events and his perception of real events, the graduate's predictions will be disconfirmed. The literature on graduates' entries into jobs suggests that "surprise" (Louis, 1980) or "reality shock" (Hughes, 1958) are frequent feelings among graduates. This has been confirmed by recent studies, which show that graduates are likely to experience surprise about their job content, the management style, and themselves (e.g., Arnold, 1990; Debden, 1986; Keenan \& Newton, 1986; Louis, 1980; Maybe, 1986; Nicholson \& Arnold, 1999). The results of these studies suggest that graduates entering employment are likely to experience some disconfirmation, and therefore they engage in constructive revision by extension. 
Constructive revision. Kelly (1955, 1970 cited by Fournier \& Paine, 1994) identified two forms of revisions:

1) Slot revision - an individual changes some elements of constructs (Fransella \& Dalton, 1990; Leitner, 1988).

2) Construct innovation - the development of new constructs to make sense of events.

The revision in personal constructs has been found in studies on subjects who spent different amounts of time in an organization or held different roles (Arnold \& Nicholson, 1991; Brown \& Detoy, 1988). For example, Arnold and Nicholson (1991) report a revision of constructs from "character-related constructs" to "interest-related constructs". They also found changes in skill-related constructs associated with the duration of work for an organisation. This proves that graduates are likely to undertake some construct innovation during the transition from school to employment.

Self-concept is a reflection of self (Goffman, 1979). It is a self-image of roles, situations or positions in one's acting or in relationship networks (Super, 1996, quoted by Savickas, 2002). Self-concepts develop from social comparison, that is, in relation to other individuals who act as a reference group. An individual compares selectively, that is, compares to other individuals who correspond to desired life goals. Self-concept is a generalized self-image. It reflects how much or how little one values one's self or how competent one is. This judgement serves as a basis for self-direction. It shows how one praises, punishes, encourages or has regrets about one's self (Mareš, 2013a).

In contrast to self-concept, self-efficacy is a more specific characteristic. According to Bandura's (1997) social cognitive theory, self-efficacy refers to individuals' beliefs about their capabilities to successfully carry out a particular course of action. Bandura explains that self-efficacy has an important influence on human achievement in a variety of settings, including health, sports, business, and in academic contexts. But self-efficacy also plays an important role in occupational commitment, i.e., an attachment to work in a particular self-efficacy role (Hackett, Lapierre, \& Hausdorf, 2001). Teachers' occupational commitments are positively associated with decisions about career paths for entering the teaching profession after graduation (Rots, Aelterman, Vlerick, \& Vermeulen, 2007). This is in accord with Eccles's (1994) claim that people choose a professional career for which they have the highest self-efficacy. Success expectation and conviction of one's abilities are important factors in shaping one's career. 
The career construction theory of D. E. Super (1996, quoted by Savickas, 2002) demonstrates a link between self-concept and a professional career. Super maintains that people differ in their abilities, personalities, needs, values, interests, traits, and self-concepts. Therefore, they are naturally qualified for a number of occupations. Each occupation requires a characteristic pattern of abilities and personality traits. The nature of a career is determined by an individual's socioeconomic status, mental ability, education, skills, personality characteristics, career maturity, and by the opportunities to which one is exposed. In the professional career, an individual decides how to manage the transition from one phase to another, the success of which depends on the readiness of the individual to cope with the demands of that phase. Career development is essentially implementing occupational self-concepts. Career decisions reflect one's attempts at translating one's self-understanding into career terms (Super, 1984). Self-concepts develop over time, making career choices and adjusting to them a lifelong task.

After describing the concepts of personal value, personal construct, self-concept and self-efficacy, a model of the career phases of a university teacher will be introduced. The model is comprised of five career phases, spanning from the preparatory phase to the slump phase. None of these phases can be circumscribed by time, age or the academic degrees of a university teacher.

\section{PHASES OF THE PROFESSIONAL CAREER OF A UNIVERSITY TEACHER}

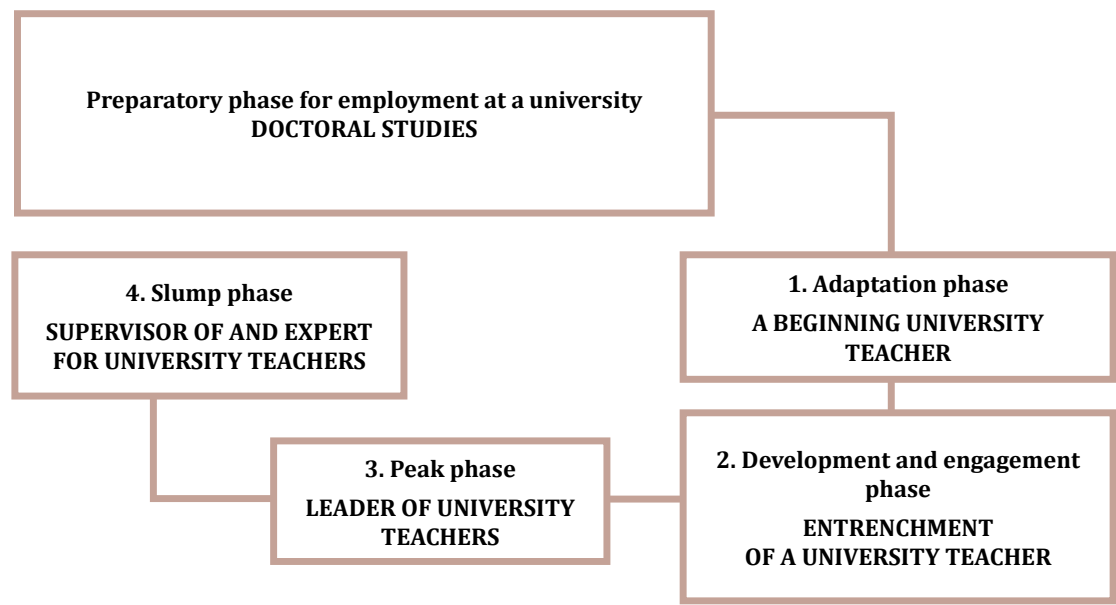

Fig. 1 Phases of the professional career of a university teacher - an ideal model 
1. The adaptation phase. In the university environment, the beginner is a newcomer to the institution who explores different activities and roles, and adjusts preferences, interests and abilities. Gradually, the individual identifies with the workplace. This phase is not easy to delineate because there are large inter-individual differences. It is as individual-specific as is self-concept, which an individual begins to create, based on social comparison. If personal construct collides with a workplace reality, and it cannot be changed, an individual leaves the workplace.

2. The development and engagement phase. In this phase, a university teacher becomes a full-fledged employee, with a developed teacher identity. He is an independent staff member and may hold certain posts in the organization's hierarchy. In addition to teaching responsibilities, the employee is expected to conduct research projects and publish. This phase suggests how a university teacher's self-concept will be shaped in the future, which factors will affect it, and how the rules of social comparison will be set.

3. The peak phase. A university teacher becomes an important staff member who contributes to the university's success. Universities engage these experienced teachers in a variety of advising and supervising tasks. They are expected to actively engage in managing the careers of their younger colleagues. However, some university teachers might feel their occupational aspirations were not fulfilled and may leave the university.

4. The slump phase. In this phase, the influence and attainments of a teacher decline in the organization. However, universities retain them as an important individual who shapes the university career.

Knowledge of these professional career phases can help in understanding aspirations and interests of employees of different ages and professional maturities. This knowledge may also serve as a basis for shaping the work potentials of an organisation regarding the management and planning of the professional careers of employees.

\section{2}

\section{Planning and Managing Professional Careers}

Professional career planning by an employee in an organisation is a process aimed at securing a required occupational position in a profession. In this planning, professional and occupational careers intersect. An individual delineates their 
growth and progression in an organisation, based on the needs judgement of this organisation. An organisation plans the professional careers of its employees based on employees' potentials, attainments, and the organisation's preferences. A well-functioning career planning system encourages employees to take more responsibility for their own development, including the development of the skills viewed as critical for the institution (Milkovich \& Boudreau, 1993).

The professional career planning of employees in an organisation must take into consideration the professional orientation of each employee. As explained in section 1.1, this orientation is determined by an employee's abilities, motivation, and value preferences.

Professional career planning is a subset of professional career management. The organisation selects employees, evaluates and orientates them in order to make the institution perform well. This is based on a management policy designed to maximize the potentials of an organisation. The policy includes whether an institution concentrates on internal employee development or whether it hires them externally. The policy also includes the decision whether to train narrowly-specialized or broadly-skilled workers and also what strategies to adopt if careers stagnate.

Besides professional career planning, which is provided by an institution, there is also an individual's professional planning, which is the responsibility of an individual. An individual's career plans should be established after careful self-assessment of abilities, knowledge, attitudes, values and experiences. This planning is more efficient if an individual can receive advice from a more experienced co-worker who can judge the adequacy of the professional career aspirations of the individual. The career plan plays an important role in establishing an individual's career goals. It is a result of self-assessment and the judgment of goal-attainment conditions.

The theoretical literature describes several career types, which have been derived from experiences from a wide range of individual professional careers. Armstrong (2002) has characterized five basic career types, which describe the characters of individual career seekers:

1 An egoist. An individual who avoids taking responsibility for the organisation's goals, and whose career is predominantly aimed at professional self-development. If the individual is offered a management post, he/she refuses, despite possibly having adequate abilities for holding it.

2 A leader. The individual's primary professional aspiration is to manage other employees. Personal development is aimed at the growth of analytical abilities and emotional engagement. The individual works long hours, takes time for networking, and seeks visibility. 
3 A conformist. The individual concentrates on acquiring a "safe" job in the organisation, which is embodied by a long-term contract. To attain this career goal, the individual quickly adopts the rules and norms of the organisation.

4 A voluntarist. The individual aims at producing original and unique achievements within an organisation. Therefore, the individual seeks a job that enables creative attainments. Frequently, such an individual accepts a managerial position that allows them to best use their creative abilities.

5 An autonomist. The individual has problems with respecting organizational rules and norms, prefers self-development over contributing to the attainment of the organization's aims.

These career types are abstractions, and may not exist in pure forms. Rather they are used in a variety of combinations. In the following chapters, I describe the accounts of the study participants, based on in-depth interviews, which document individual career planning and managing. Chapter 6 presents specific details about their career trajectories. 


\section{THE PURPOSE AND ACTUALISATION OF THE STUDY}

\section{1}

\section{Research Methodology}

Educational research has accumulated rich data about the studies and lives of doctoral students (Davis, 2003; Gardner, 2007; McAlpine, Jazvac-Martek \& Hopwood, 2009; Turner \& McAlpine, 2011; Jaraim \& Kahl, D., 2012; Neusar, Charvát et al., 2012; Vekkaila, Pyhältö \& Lonka, 2013). A wealth of information has also been collected about postdoctoral years (Melin, 2005; Mareš, 2013b, Åkerlind, 2014). The results of such investigations will be referred to throughout the book. Data concerning the professional paths of university teachers in the Czech Republic after completion of a doctorate are scarce. Some findings were published by Šed'ová et al. (2016), but they primarily concentrated on the quality of teaching and self-concept of young teachers at one Czech university.

This book provides an in-depth examination of the occupational and professional careers of young university teachers. The data illustrate what they experienced after being employed at a university, how they work within the system and how they see the influences and contexts that affected them in the university environment and beyond.

\subsection{1}

\section{Aims of the Study}

The aim of this work is to understand the process during which university graduates become university teachers. 
This broad aim is subdivided into two specific aims:

1. To describe the developmental phases in occupational and academic careers of young university teachers.

2. To describe the external and internal factors that determined the professional growth of young university teachers.

This study concentrates on participants who completed a doctorate and then became a teacher at a university. The occupational and professional careers of some of them were not straight forward, but included digressions, critical moments, situations and events that dramatized the careers and brought strong professional and personal challenges and stimuli. My intention was to capture and describe these career situations and moments - as they were reconstructed in the participants' accounts.

The participants acted and were developing in concrete occupational and professional environments. In the beginning, my intention was to concentrate only on the personalities of the participants, however, during the investigation - in harmony with the canons of qualitative inquiries - it appeared fruitful to broaden the scope and describe how the occupational and professional environments function, as viewed by study participants. So another aim became to present the university environment as a domain in which occupational and professional careers intersect.

The study aims are limited by the field of investigation. The exploration of becoming a university teacher was restricted to graduates in pedagogy. Therefore, their processes and determinants are bound by this discipline, though some data and their interpretations may extrapolate to other domains, at least by suggesting new questions for future investigations.

\subsection{2}

\section{The Study Participants}

The sample consisted of ten adults who were employed at universities in the Czech Republic at the time of the study. There were seven females and three males, belonging to the same generation of university teachers.

They shared these characteristics:

1. Age (between 27 and 40)

2. PhDs in pedagogy

3. Employment contract at a university in the Czech Republic

4. Commitment to sharing their academic and vocational experiences with me.

5. Provision of oral consent with participation in the study. 
At the time of the investigation, the study participants worked at the university a maximum of five years. They were contracted for the position of a university teacher, i.e., not for the position of a postdoc. Their job responsibilities included but were not necessarily limited to the following:

- instruction

- research

- publication

- administrative duties.

Thus, the sample consists of university teachers who have already been integrated into the professional community and have been published. In the recruitment process, I invited fifteen university teachers to participate in the study. However, only ten consented. These constitute the sample. The reasons for refusal was lack of time or some unclearly-stated concerns about privacy.

The following sections contain individual characteristics of the study participants, starting with the three men.

\subsubsection{1}

\section{Men in the Study}

\section{MAN “D” - five years after earning his PhD (hereinafter referred to as M1)}

He earned his master's degree from a faculty of arts. His first job was in an institution for problem children. Later he taught at a primary school. However, he found the primary school environment inappropriate. He was disappointed with the way the school was administered, and his vision of the school staff was much different from the reality he encountered at the school.

After four years he entered a full-time PhD programme at a teacher training faculty. A coincidence of circumstances led to him being offered a position as instructor at the faculty which, in turn, caused him to transfer to the part-time PhD programme, thereby prolonging his studies.

He took part in several research projects, mostly helping with administrative tasks. In doing so, he learned to manage enormous administrative and organisational jobs. However, engagement in hard assignments and his high personal commitment in them delayed the writing of his dissertation. He finished the PhD programme in seven years instead of four. However, he perceived the length of the study as an advantage.

Currently, he has the position of assistant lecturer. In his research, he concentrates on instructional media and is interested in qualitative research. He prefers 
team work, and he appreciates effective management of the workplace. To perform his duties effectively, he needs an excellent social background and motivated colleagues. He is single and has no children.

\section{MAN "P" - five years after earning his PhD (M2)}

Upon graduation from a master's programme in sociology at a faculty of arts, he entered the full-time doctoral programme at a teacher training faculty. He showed excellent teaching skills soon after joining the department and taught much-needed courses. His good reputation brought him a full-time teaching position at the faculty. This, however, negatively affected his research and caused him to neglect his dissertation. He was burdened with organisational and administrative tasks, which he dutifully performed. After two years of teaching at the department, he transferred to the part-time PhD programme.

He got married during these studies and became a father. This accelerated the writing of his dissertation. He finished his $\mathrm{PhD}$ in seven years.

Soon after his dissertation defence he took up a new position: vice-dean for academic affairs. His major task was to prepare materials for accreditation of all programmes. This created opportunities for him to meet people and become engaged in research and professional development projects. However, the academic position brought about changes in interpersonal relationships, and he gradually found himself caught up in the turmoil of academic politics. Currently, he views this period of his life as both demanding and valuable. While holding the position of vice-dean he learned to be assertive in presenting and defending his views, and he learned to argue and seek compromises that would help the faculty and its members.

He is an advocate of qualitative methodology, which he intends to use in a project he was preparing with his colleagues.

\section{MAN "R" - five years after earning his PhD (M3)}

He completed his doctoral studies in pedagogy, though he was assigned to the Department of Technology Education. He earned his master's degree in this field, and his relationship to pedagogy evolved bit by bit. After graduation, he enrolled in a pedagogy $\mathrm{PhD}$ full-time programme. His supervisor was rather authoritarian, prompting $\mathrm{R}$ to be subordinate. Now he views pedagogy as an important component of his work in the department of pedagogy, where he started to work after completing his PhD. He desired to gain a postdoc position, but such a post was not available in his field. He appreciated the opportunity to stay at the department because he had had minimal job chances in his major field. He is therefore grateful to the university and attempts to meet all the criteria to maintain his position. 
He enjoys teamwork, seeks opportunities to conduct research projects, and likes to discuss them - often bringing fresh ideas to the topic. He wishes that pedagogy adopted new technologies because he is convinced that technology helps in every possible task. He views technology as a communication channel. He prefers qualitative research. At the time of the interview he was single and had no children.

\subsubsection{2}

\section{Women in the Study}

\section{WOMAN "E” - four years after earning her PhD (F1)}

Long before completing her master's degree programme she decided to continue studying to earn a PhD. Though she started to work as a music teacher in a primary school after earning her master's, she felt that this job was far away from her professional ambitions. She applied for admission to the doctoral programme in pedagogy, and was admitted as a part-time student. Her studies took seven years. Her desire to study in this programme was motivated by a role model - her grandfather, a reputable university teacher and researcher. During the doctoral programme, she continued teaching in a primary school. Initially, her supervisor did not fully support her advancement in the programme, but she was ultimately able to win him over.

After completion of the PhD programme, she was hired by a university. In her department, she had to teach topics outside of her specialty. She adapted to the new circumstances because her desire to remain in academia was strong.

Currently, she is engaged in topics related to her studies. She has written several articles and book chapters.

\section{WOMAN “I” - two years after earning her PhD (F2)}

She was admitted to the full-time PhD programme immediately after receiving her master's degree. Because she needed a paying job to help support her family, in addition to her university studies, she taught in three successive secondary schools. Her PhD programme was her priority, and she accommodated her teaching to it, which disappointed the schools' administrators and led to her job hopping. Her doctoral supervisor was on maternity leave and was of little help. She completed her PhD programme in four years, much earlier than usual for part-time students. She immediately received a position as assistant lecturer. She is now a member of a team conducting a large university research project. She frequently engages in debates with colleagues in her professional areas, and she especially likes discussions on research methodology issues. She favours qualitative enquiry. 


\section{WOMAN “K” - three years after earning her PhD (F3)}

She graduated with a degree in early childhood education, having appreciated the well-designed structure of her master's degree programme. Afterwards, she began to teach in a primary school, where she became involved in institutional projects, which stimulated her desire to further develop professionally. While still teaching at the primary school, she collaborated with a university and later applied for admittance into a full-time doctoral programme - and was offered a teaching job. She took the job and started a part-time PhD programme that she completed in seven years. She described her supervisor as an "amiable" person who guided her to be more independent in her learning and accept challenges from various areas of academia.

Soon after becoming a university teacher, she was offered the position of vicedean. Because of her young age and lack of management experience, this was an unusual appointment. But, the university was young and did not have enough talented administrators from whom to select. She held the position for two years before quitting to pursue research projects.

\section{WOMAN “L” - four years after earning her PhD (F4)}

She completed her master's in arts, and her transfer to pedagogy was arduous. She attended a full-time $\mathrm{PhD}$ programme in pedagogy, and after three years she was offered a teaching job at the same university department. She was fully engaged in developing a programme of drama education, which distracted her from doing her own research. She completed the PhD programme as a part-time student in seven years. Her supervisor had scarce contacts with her. In fact, her dissertation was written without his help. Consultations with colleagues proved the most valuable.

Although single, she sees herself as a team player. She feels most comfortable working among like-minded individuals. The highest benefit for her at the university is contact with students. They energize her, which supports her day-to-day teaching routines.

\section{WOMAN “V” - four years after earning her PhD (F5)}

She completed her full-time PhD programme in four years. Then she was offered a teaching job at a teacher training faculty where she is now employed. Her supervisor was not a specialist in her dissertation topic, so she did not receive much professional support from her. She worked alone, which helped her develop her own potentials. Later, she gained much support from an external specialist whom she consulted about her topic.

She is a single mother, and when she was on maternity leave she kept in contact with her department. She had to struggle to earn enough money to support her small family. Now she is a university teacher and has her first doctoral student. 
She hopes to concentrate intensely on research and is searching for a sufficiently-interesting and original topic to investigate.

\section{WOMAN " $P$ " - three years after earning her PhD (F6)}

On completion of a faculty of arts master's programme, she began teaching at a secondary school. Later, she attended a part-time doctoral programme. She found teaching at a secondary school too demanding, so she applied for and received a job at a university. Originally, her dissertation expanded upon her master's thesis topic. But after she joined a government-funded research project team she decided to turn to a different topic - an influence of teamwork within the project. However, the work in this team brought many administrative and organisational assignments that deprived her of time to do her own research. Her supervisor did not sufficiently guide her through her studies and research, so she shouldered the burden. She viewed the doctoral studies as self-study.

She sees good prospects for her professional career at the present department, although she worries about the increasing demands of universities in teaching load and publications. She is married with one child.

\section{WOMAN “Z” - two years after earning her PhD (F7)}

She studied in a part-time $\mathrm{PhD}$ programme, refusing the option of full-time study because she wanted to be faithful to the primary school at which she was teaching. It was her sister who served as a role model for deciding to start the doctoral studies. Also, the school director supported her studies, believing she could transfer the new knowledge to her classroom. In fact, the knowledge she learned in the doctoral programme positively affected her teaching style. She had an admirable relationship with her supervisor, and found the consultations "enjoyable".

She applied for a teaching position at a university for two reasons: she wished to test her knowledge and experience on university students, and she wanted to draw as much as possible from the academic environment for her professional growth. However, she was disappointed with the climate at the university, which she found much different from that of primary schools. She missed working with children. She left the university after one year, taking a teaching job at a private secondary school. 


\subsection{3}

\section{Research Method}

The research method in this study was an in-depth interview. In the preparatory phase, the content frame of the interview was constituted. The frame consisted of topics as follows:

- motives to study for a doctorate

- doing coursework

- conducting dissertation research

- writing the dissertation

- views of university teacher responsibilities

- identification with the position of a university teacher

- identification with the position of a researcher

- views of the next phases of the professional career.

\subsection{4}

\section{Performing the Interview}

The participants provided informed consent. The purpose of the study and the circumstances were explained to them, including how their anonymity would be protected by the researcher. The place and the time of interview was negotiated.

The interview consisted of a set of questions generated from the thematic domains. Many questions emerged during the interview. The first few interviews convinced me of the relevance of the thematic domains. Gradually, the questions became more aim-directed and clearer. My strategy was to let the interviewee talk continuously, as interruption-free as possible.

Only two identical questions were posed to all participants, the first and the last. The intention of the first question was to draw the participant into the interview. The question was, "How do you recall your doctoral studies?" It elicited recollections and thus served as an efficient stimulator. The last question, "What will you recall tonight about our meeting?", aimed at participant self-reflection.

A specific feature of the interview was that the participants themselves have had experiences with empirical research, so they critically followed how I was managing the interview. They observed my verbal and nonverbal communications and probably evaluated them. Being aware of this "participatory monitoring" brought a certain burden to my interview conduction. 
Another specific feature was that the participants themselves posed questions to me. This also may be attributed to the research experiences of the participants. For instance, they frequently asked a question like, "How was this in your case?". This can be interpreted as testing the researcher and as an effort to gain a stronger position in the conversation. Sometimes, the participants posed questions because they were unable to answer my questions. Interestingly, such questions were only asked by women.

The interviews generally took place at the participants' "home universities" and in their offices, to increase their comfort. There were two exceptions: two male participants agreed to be interviewed outside of their workplaces, but still at a university, a relatively familiar environment. The duration of the interviews was dictated by time constraints of the participants, albeit with a minimum requirement of one hour.

Each interview was recorded on two voice recorders, which minimised losses in case of the failure of one recorder. Transcripts were made from both recordings by two assistants, and the two versions of the transcripts were compared for accuracy. Discrepancies were resolved in discussion. As a result, a single transcript was made from the two.

To begin with, I organized an unrecorded informal initial conversation with each participant, during which I explained the purpose of the study. The participants were encouraged to ask questions, which they did. The questions concerned, for instance, the implementation of the research findings. The participants were assured that no personal information would be misused. Privacy was protected by anonymising the transcripts.

After the formal interview, an off-record conversation usually took place in which the participants asked more questions usually related to my personal experiences with a PhD programme or my work at the university. This part of the session took as long as one hour. For both the participants and myself, emotions accumulated during the interview, which were necessary to release. The post-interview, offrecord conversation served this purpose.

There exist several styles of conducting an interview. Concerning this study, I would refer to my style as a listening colleague.

\subsection{5}

\section{Transcription}

After the completion of the interview sessions, transcripts of the interviews were created. A transcript is a conversion of an oral record into written form. 
This conversion is a pragmatic matter. Analysis of transcripts is more comfortable than that of a sound recording. In the written text, one can easier locate necessary segments, and the written format enables the coding procedure and the inclusion of the researcher's memos.

Transcripts are prepared according to rules, which constitute a system that guarantees the uniform conversion of all records into the written form. Thus, transcription constitutes a reliable tool for data analysis. There exists a variety of transcription systems used in qualitative investigations, which differ by approach to data and degree of detail. The selection of the system is determined by the aims of the investigation and the researcher's theoretical perspective. For instance, in conversation analysis (G. Jefferson, 2004), researchers use a narrow transcription, which captures both the verbal content of the speech and paralinguistic features such as emphasis, pitch, length of pauses (measured in tenth of seconds), etc. Many qualitative researchers do not need such a minute transcript; rather they concentrate on the content of the speech. This was also my case.

The transcription rules used in my study were as follows:

1. Accurate verbatim verbal content of the participants and the researcher, including incomplete words and "repairs".

2. Expressions of agreement ("mhm") and hesitation ("ehm").

3. Pauses longer than 3 sec. (“...")

4. Laughter ("laugh").

5. Incomprehensible segments caused by mispronunciation, external noise, etc. ("incomprehensible")

These transcription rules proved satisfactory and fully functional for the analysis.

\subsection{6}

\section{Data Analysis}

The analysis was based on a recursive reading of transcripts, through which I gradually immersed myself into the thinking and opinions of the participants and created a global view of them attempting to understand the interview as a compact whole (Pope et al., 2000). I made frequent interpretative memos, highlighted important segments and looked for relationships among them. Gradually, I constructed a memos system for the next phase of data analysis (Miles, Huberman \& Saldaña, 2014,p. 93). My way of analysis resembled the model described by the Finnish scholars Backman and Kyngäs (1999, p. 149): 
Data analysis is like a discussion between the actual data, the created theory, the memos, and the researcher. Such discussion takes place when the data are broken down, conceptualized and put back together in new ways. The data give rise to the codes and the categories, which combine the codes. The categories and the hypotheses must be verified against the data by comparing the categories with each other, with the data and with the researcher's conclusions.

In the analysis, I used the principle of induction, the advantage of which is the potential of revealing new perspectives on the investigated raw data. In this way, new categories were created and relationships among them traced.

While reading and analysing the transcripts, first of all, sensitive segments were identified, i.e., those pieces of text that seemed the most relevant. These were then attributed labels, or codes. The segments varied in respect to length, but none was a single word: rather, they were chains of several words. For instance, codes were "rules of supervisor-doctoral student communication," "collision of two jobs," or "desire to become a university teacher". After having identified a certain amount of codes, they were systematized and grouped according to the meaning they carried, and then were hierarchically ordered. For instance:

\section{Phases of the doctoral study}

Motivation for enrolling in the doctoral programme

Acceptance of the role of doctoral student

Writing the dissertation

Integration into the professional community

By grouping the codes, large categories were constituted (in the above case, Phases of the doctoral study), which had the potential to integrate group codes. After the categories were constituted, I returned to the codes, checked them and returned back to the categories. Strauss and Corbin (1999) referred to such a procedure as "constant comparison".

Category creation is an interactive process in which the relevant role is played by the data and their understanding. Elliot and Timulak (2005, p. 154) refer to this process as "dialogue with data". Understanding the data was accompanied by studying the literature, both research papers and theoretical works. Large categories that appeared in the second level of analysis became the core of chapters of this book.

Collegial coding was an important component of the analysis. This coding is a method of data triangulation and serves the purpose of strengthening the credibility of the analysis output. In collegial coding, the emergence of codes is traced, 
and the adequacy of their labels are assessed. In my case, collegial coding was performed by another researcher, who independently coded the same transcripts.

Coding, or in fact the entire data analysis in qualitative research, is a considerably subjective matter - the researcher projects in it their personal perspectives and experiences through which they interpret the data. This is not a shortcoming but rather an advantage of qualitative enquiry. Collegial coding of a transcript rarely brings identical outcomes (Švaříček \& Šed’ová, 2007), a fact confirmed by this study. Due to lack of time, however, only two transcripts were collegially coded. This resulted in two independent systems of codes, which differed in the placement of the codes in the text, their density and labels. After finishing open coding, the two researchers compared the codes, identified agreements and differences and discussed their possible reasons. This comparison was found useful because it enabled me to re-trace my trajectory of steps which, in turn, supported my interpretation conviction.

Theory construction is an important component of qualitative enquiry. Theories were being developed continuously in the data analysis and were accompanied by drawing diagrams of categories. These diagrams underwent changes in every phase of the analysis.

The researcher should seek opportunities for discussions with professionals, as I did. Diagrams that portrayed my theory have been presented in several professional events both in this country and abroad and were discussed with colleagues. Thanks to these discussions and to links to the theoretical literature, I was able to constitute my theory, which is described in this book. 


\section{DOCTORAL STUDIES OF THE STUDY PARTICIPANTS}

In the Czech Republic, being a university teacher is generally not prestigous. Most young people do not aspire to acquire the knowledge needed for teaching, research and publishing, but a minority of young people, for various reasons related to their personal constructs and self-concepts, do desire an academic career at the university level. Such young people became my research focus. Their professional careers started with doctoral studies.

Doctoral studies aim to prepare an individual for scientific work. The doctoral programme has a less rigid composition than the master's programme because it is targeted primarily at gaining research experience rather than acquiring knowledge in courses. The programme is not tightly structured, which does not mean that it has no rules and regulations.

Doctoral studies represent the highest level of the university education and aim to teach advanced knowledge about research planning, strategy, and methodology. Most scientific fields have specific investigation purposes, which determine the research methodology choice. Educational research is no exception. It centres on the systematic description, analysis and explanation of "the educational reality", which is composed of the "educational environment", "educational constructs" and "processes" (Průcha, 1997). For research purposes, it uses a wide range of procedures and methods.

The doctoral programmes have top standing among study programmes. A Czech university, which has an accredited doctoral programme, can be characterized by

- a higher scholarly status,

- a larger amount of state subsidies (state universities are funded for a number of students),

- the right of awarding grants for doctoral student projects, 
- a higher publication rate (publications by doctoral students contribute to the university's total publication production).

Recently, the accreditation awarding committee of the government of the Czech Republic monitored the quality of universities that offer doctoral programmes. It assessed teachers, programme coordinators, supervisors, research, publications and dissertations. The motive for this review was a recent decrease in the number of pedagogy doctoral programme graduates (Mareš, 2013b).

This decrease was attributed to several reasons:

1. In the Czech Republic, the prestige of science and research is low, in spite of its proclaimed importance in the media.

2. There is a tension between the evaluation and funding of hard and soft sciences. The assessment criteria for hard science production, which are, in principle, applied universally, disadvantage soft sciences. Science and technology research is preferred because its findings can affect more directly the production of companies, and contribute to the nation's economy. The research in social sciences does not produce inventions and patents, so it seemingly does not bring benefits for companies. This situation was commented on by one of the study participants:

In science, evaluation is different from that in social research. I must say, we're handicapped. Generally, the new technology and production processes are favoured. How can a history study compete with them? (M2) ${ }^{1}$

3. The workplace practice of employees is more valued than their degrees. A PhD graduate is a more expensive workforce than a graduate with a lower university degree. As the graduates have little-to-no practical experience, they require special training to develop workplace skills, which is a burden for a company. Occasionally, this results in paradoxical employment strategies:

I might have problems with my degree. Most of my older colleagues complained that they had. They concealed their degrees in order not to be refused by an employer. They are an expensive workforce and have high employment demands. (M3)

In contrast to the students who enrol in the doctoral programme, graduates with lower degrees may enter into employment earlier. This brings three advantages:

1 All respondents' quotes have been translated from Czech to English. 
- They accumulate more workplace practice.

- They make earnings, and thus can establish a family.

- They may support parents financially (a tradition in the Czech Republic).

For these reasons, to decide to enrol in a doctoral programme is not an easy matter. The decisions regarding enrolment deserve a thorough analysis. The following questions should be answered: What are the motives for enrolling in the doctoral programme? Will doing so bring an employment advantage? The answers to these questions are the core of the following chapter.

\section{1}

\section{Why did I Enrol in the Doctoral Programme?}

Motivation is defined as the process that initiates, guides, and maintains goaloriented behaviours. More specifically, it is a psychosomatic process that directs a person to behave and react in a way that helps them to saturate certain unfulfilled needs (Latham, 2011). It comprises both internal and external factors "that activate or maintain an individual's behaviour" (Shafritz, Koeppe, and Soper, 1998, 303). At a specific time, motivation can be stable, while at another time, it can change depending on circumstances. This chapter is focused on motives for enrolling in doctoral studies, as reported by the study participants in the interview.

Basically, this motivation is influenced by two factors:

a) Macrosocial, such as a chance to find a job in the labour market, and the social climate.

b) Microsocial, such as the university system, experiences gathered in a master's degree programme, personal maturation, and one's convictions.

There are two types of motives for enrolment in a doctoral programme, intrinsic and extrinsic, each is divided into submotives:

1. Intrinsic
a) Continuing studying after earning a master's degree.
b) Becoming a researcher.
c) Attaining a high reputation in a study field.
d) Prolonging the student lifestyle.

2. Extrinsic motives
a) Getting a job at a university without having workplace practice.
b) Following a role model.
c) Fulfilling the advice of important "others" (parents, friends). 
In contrast to the decision to become a teacher at a preprimary, primary or secondary school, which is usually based on intrinsic motivation (see Kosová, 2013; Lukášová, 2015; Wiegerová \& Gavora, 2014), the desire to become a researcher is based on both types of motives. Šturzová (2006) provides evidence on the following key motives for enrolment in a programme:

- desire to expand one's knowledge,

- desire to build an academic career,

- getting a job,

- salary, albeit a modest one (Šturzová, 2006).

In contrast to the decision to become a primary or secondary school teacher, which is often influenced by altruistic reasons (Bruinsma \& Jansen, 2010), in starting a research career, materialistic motives exist. This is documented by a statement from a study participant:

A reason to enrol in a doctoral programme was to receive a scholarship, though a small one. This was a good option in case I would fail to find a job. Eventually, I was not looking for any. (F5)

Universities play a key role in influencing a student's resolution to enrol in a doctoral programme. As early as in master's classes, teachers seek out and support talented students who might enrol in doctoral programmes (in this case the word "talented" may be an exaggeration, though traditionally used in academia). Important motivational factors for enrolling in a doctoral programme are an individual's family situation, one's convictions, ambitions, self-concept, and personal constructs. The following chapters describe motivations from a university and from a family, as well as one's own conviction to enrol.

\subsection{1}

\section{A University's Motivation for Encouraging Enrolment in a Doctoral Programme}

As mentioned, Czech universities are motivated to seek excellent students for doctoral programmes. Of course, they do the same also at lower levels of study, but in the doctoral programme the effort is more intense. The interview data document the university's motivations to recruit students. 
The first impulse came from the university administration. They asked me whether I'd like to continue studying at the doctoral level and, at the same time, to accept a job at the university. So this was my primary decision. (F5)

My master's thesis supervisor asked whether I wished to continue my studies and enrol in a doctoral programme. I said "Why not." (M3)

A student's resolution to enrol in a doctoral programme may be supported by appreciating the emotional climate that prevails at a university. This factor was described by the study participants:

I enjoyed staying at the university. I wished to be with people whom I liked. (M3)

For me, the faculty was a charming place. I wanted to remain there. (M5)

Ružička (1992) describes the role of a "motivational profile" as a relatively-stable preference for making decisions. Thus, it is important that young individuals link their personal constructs to an institution that would become their workplace. If the university is aware of this link, it can adopt strategies to attract individuals to a doctoral programme. The study participants' routes to this programme were influenced by their master's programme teachers and supervisors:

It was my master's thesis supervisor who encouraged me, pleaded with me, and finally convinced me. He then became my doctoral dissertation supervisor. (M3)

This situation implies that a future supervisor also provided assistance in the candidate's admission preparation. Their discussion topic was the dissertation project. This, however, need not be a rule if candidates are employed and are interested in the part-time programme. They are highly motivated and are active in finding a university that matches their interests. They have a desire to be experts in their fields, achieve a good standing, fulfil their ambitions, strengthen their self-concept and support their professional careers.

Some of the study participants wished to change employment, and a PhD served as a tool to achieve this goal. An applicant's high self-efficacy may be another relevant motive that supports the decision to enrol in a doctoral programme. The following quote is from a study participant who had an excellent reputation as a primary school teacher before enrolling in a doctoral programme. 
My colleagues told me that I was a good lecturer and that I do things that would be appreciated at a university. This made me think of enrolling in the doctoral programme. (F7)

The doctoral programme accreditation documents include, among other things, admission criteria. They serve as a basis for the applicants' admission strategies. The study participants reported three kinds of admission procedures:

1. The full-scale admission procedure.

Well, I wanted to study in the full-time programme, and I submitted a formal application at this department. The doctoral programme board reviewed my dissertation project. Also, I had to attach documents to prove my competences, my master's degree diploma, and they wanted me to decide whether I would study full-time or part time. And they made the decision. (M1)

To be admitted to the doctoral programme, I had to undergo the admission process [in inverted commas]. The admission board reviewed my dissertation proposal and then made the decision. So it was a dissertation topic, a dissertation project, followed by an interview with the board. I am thinking of anything else - only some supporting documents, curriculum vitae, which were also reviewed, and nothing else. (F2)

2. No admission procedure if the applicant had excellent study credentials, for instance, a diploma of distinction.

In order to be admitted to the doctoral programme, I took part in the student research competition. I was granted a diploma of distinction and my master's thesis was awarded. (F5)

3. No admission procedure if the university greatly needed doctoral students and therefore did not bother reviewing the applicants' study potentials.

The professor coaxed me, he suggested a good topic... I was unable to decline... and this is all I can say about the admission... (M3)

The study participants did not mention the possibility of studying abroad as a motivating factor. Such opportunities are offered by universities within the framework of exchange programmes. Their reason for lack of interest may be that travelling 
abroad is no longer an exceptional benefit for the younger generation. Young people's ambitions and chances are different from those of a decade or more ago. Travelling abroad is a standard component of their lives, and therefore they do not need to compete for a study abroad opportunity.

A university attracts individuals to enrol in the doctoral programmes especially by having the following:

- outstanding programme reputation,

- excellent teachers,

- excellent supervisors,

- favourable climate that supports self-development,

- reasonable admission procedures.

A university can support the commitment of young people by offering a wide array of arrangements to support their studies:

- participation in subsidised research projects,

- research assistantships,

- scholarships,

- awards for excellent dissertations.

Not only are the students motivated to enrol in the university's programme, but the university itself is motivated to accept students. It needs doctoral students to gain funding and credibility and to improve its profile. Doctoral students increase the state subsidies allocated for each student, which, in turn, strengthens the university economically. Having doctoral students also brings the university a good reputation within the professional community.

\subsection{2}

\section{Family as a Source of Motivation for Enrolment in a Doctoral Programme}

In the final phase of the master's studies, family may play an important role in influencing the career decisions of young people. They might get married and establish families, so the view of prospective employment with a $\mathrm{PhD}$ is a relevant decision criterion for them. If students have spouses and children, their decisions are even stronger. Family circumstances appeared to be a strong motive of the study participants: 
I wanted very much to be an important supporter of my family. So I decided to enrol in the doctoral studies. (F7)

Students, who had no spouses and children and decided to enrol in full-time studies, often prolong the student lifestyle. They maintain the social and financial benefits available to students. This student motivation has an increasing tendency. In the Czech Republic, many young people are still closely linked to their parents, siblings, and grandparents. The immediate family's favourable attitude to the young person's further studies brings them a feeling of security. Family support is one of the vital factors in the decision to enrol in a doctoral programme.

Mother and father were proud of me when they saw me receiving the master's degree diploma at the ceremony. My decision to further my studies was simple. My parents supported it. (F3)

A family member may serve as a role model that directly motivates the young individual towards a future profession, a route to which is doctoral studies.

My grandfather was my role model. He sits on the scientific board, and he frequently spoke about it. He is a professor. However, I concealed I wanted to study. He did not have the faintest idea of it. But then he became proud of me. He was always motivating and supporting me. (F1)

I come from a teacher's family. My father is a teacher. He used to say that a teacher is like an actor. He must have a talent. Father motivated me to enrol in further studies. (F2)

These statements document scientific and teacher role models. In the first quote, the granddaughter wished to prove her potential to her grandfather by following in his professional footsteps. In the second quote, the young woman expressed a desire to follow the model of her father.

In these cases, family functioned as a cohesive factor. It did not only provide role models but also supported professional socialisations by recommending further studies that would develop abilities and increase the probability of success.

The study participants' accounts documented three family functions:

1. Provision of material assistance.

2. Provision of emotional support.

3. Provision of a professional role model. 


\subsection{3}

\section{Conviction to Become a Student in a Doctoral Programme}

The desire to succeed is a strong factor in deciding to become a student in a doctoral programme. Desire and motivation are closely linked to satisfying personal needs. Usually, a need arises if the balance in the social milieu is broken. This may happen if new circumstances appear. If individuals lack some important factor, they feel impelled to make changes in order to meet their needs (Mareš, 2013a).

The study participants reported the following needs to be met:

a) A need to belong to the academic community. They became acquainted with this community during their master's studies. They wanted to be active in academia and were aware of the traditions that govern it.

Well, my most important motivation was to be an academic, so that I could be actively engaged in research projects. This was the highest motivation. I knew I wanted to remain in the academic world. If I didn't have this motivation, I would have found a job and would not have begun the doctoral studies. (M3)

b) A need to perform research. The study participants wanted to join professional teams in order to engage in interesting conversations.

I want to work with people who are good at discussions, I desire to learn communication, investigate people's opinions and attitudes. I like this academic environment; it is both loose and bound. But I love it. (M1)

c) A need to acquire knowledge, gain experience, and have a chance for selfrealisation.

As a student, I've read volumes of books in my field, and I knew I wanted to do this. (M2)

d) A future vision - a clear view of future work and employment.

I want to be in this community, I want to stay at a university. I enjoy it and I want to develop my abilities. (F1) 
The study participants' conviction to start a doctoral programme was determined by meeting the following needs:

- epistemological,

- social,

- attainment,

- self-realisation.

An effort to pursue the doctoral programme was linked to a variety motives, such as,

- to prove one's potentials to oneself,

- to prove one's potentials to the community,

- a desire to attain a higher position,

- a desire to change employment, if dissatisfied with the current one.

My decision to study was associated with the wish to avoid teaching at primary school. (F1)

The lack of time [at school] bothered me. Also the noise during breaks. I felt my potentials to be higher, and people around me supported my decision. (F2)

Similar motivational factors were identified with students at Masaryk University in Brno, Czech Republic. Using a questionnaire, the investigation revealed that the resolution for studying in a full-time programme was determined by these factors:

- a student's own decision,

- conversations with university teachers,

- interest in the scientific work (Neusar et al., 2012).

This investigation focused on the perception of one's studies, self-assessment of professional knowledge, instruction and career plans. Thus, it was similar to my research.

\section{2}

\section{Am a Doctoral Student}

The goal of the study participants was to become doctoral students. This chapter describes the roles and positions they acquired after they enrolled in a doctoral programme. They expected that the path from master's to doctoral studies would be straightforward and trouble-free. This assumption turned out to be false. 
As the data show, their desire was to become researchers. For some of them, doctoral studies represented the first phase in their goal trajectory; for others, the second. In the latter case, these students transferred from the full-time to the part-time programme and became university teachers. On the route to becoming researchers, they acquired new social roles and began their integration into the professional community.

\subsection{1}

\section{Acquiring the Doctoral Student's Social Roles}

The acquisition of a social role is a non-linear, rather complex process, occurring over a range of experiences. Some experiences occur collectively, some individually, some are formal parts of a study programme and others happen informally, some of them happen in random order and others are strictly sequential (Austin \& McDaniels, 2006).

Socialization "is a dialectical process through which newcomers bring perspectives, values, and ideas that interact with the expectations within the organization'” (Staton, 1990, quoted by Austin \& McDaniels, 2006, 41). "While novices are learning about the organization, their involvement and interactions should also lead to organizational change" (Smart, 1985, 401).

After entering into the doctoral programme, the study participants expected to acquire a different role when compared to that of a student in a master's programme. They had high expectations of their teachers' attitudes and behaviours, which, however, were not met. They found this situation uncomfortable.

I know that I was a student, but I obviously expected that colleagues would behave differently (F2).

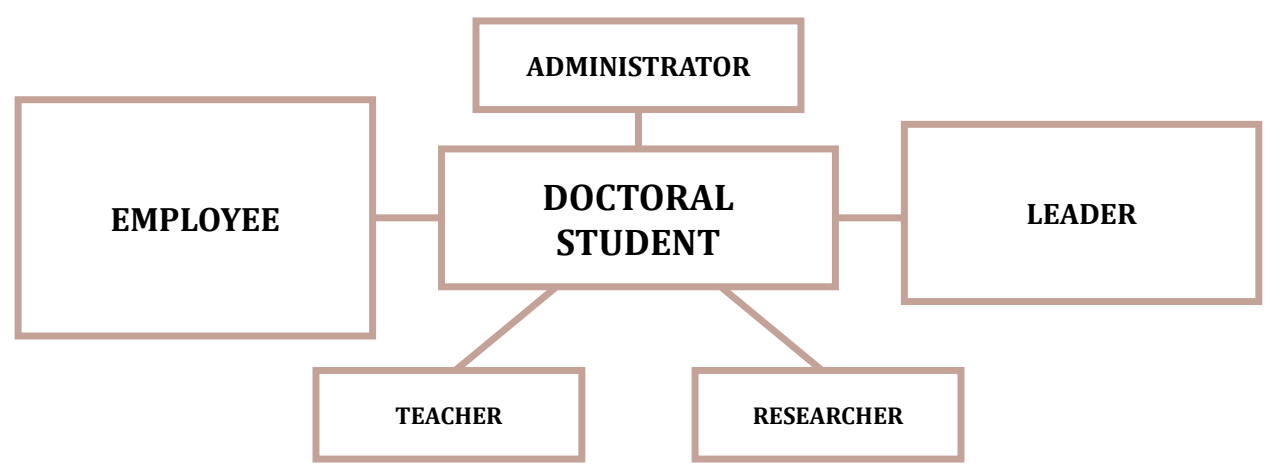

Fig. 2 The doctoral student's roles 
In their accounts, the study participants reported the following roles (Fig. 2).

- students,

- researchers who were working on their dissertations,

- teachers who taught courses,

- employees at a university,

- university administrators.

These roles are similar to those reported by Neusar et al. (2012). However, the participants in my study acted also as leaders. They became vice-deans, department heads or heads of institutes. The Brno study participants were also organisers of outreach programmes, which was absent in my case (Neusar et al., 2012).

\subsubsection{1}

\section{The Student's Role}

By transferring from the master's to the doctoral programme, the study participants preserved the student's role. They maintained student benefits, such as financial and material support provided by the university and the government (e.g., scholarship, reduced travel fare), and they continued to experience a student life-style - something like an extension of carefree adolescence.

Doctoral studies were one of the most beautiful periods in my life. In fact, they were more beautiful than the master's studies. I really experienced pleasant moments. Though we had to pass examinations, other enjoyable things prevailed. I felt I was still a student. (M3)

The next quote reveals an opposite tendency: the individual wanted to abandon the student's role. She did not want to be "only a student". The same tendencies appeared with other doctoral students, all of whom were females. This can be attributed to their maturity and a desire to actively shape their careers. These participants were part-time students and were employed; some of them were university teachers. This, in part, explains their attitudes towards the student's role.

The study participants spoke critically of the quality of the doctoral programme:

My expectations about doctoral studies were different. I had a different image of it. Truly, there were excellent conditions for an independent work, but not as excellent as in the master's studies. I expected greater support, also more courses on research methodology. (F3) 
Well, it was quite loose, nobody was interested in us much. We had a list of required courses, but it was shorter than that in the master's studies. I view the doctoral studies as a self-study. (F6)

Doctoral students were able to use their extensive free time for employment, for instance, teaching at a primary school, a frequent option of the study participants. Some students anticipated a stricter management of doctoral studies. They did not acquire methods of independent learning in their master's studies, and now they were astonished when left alone. Having low time-management skills, they had problems to schedule time to complete their courses and work on their dissertations.

This shows that it is a must that a doctoral student possess the time-management skills necessary to make reasonable schedules to meet the study requirements. Doctoral students must understand the study rules and must assess their abilities to act in the role of a doctoral student.

Besides time-management skills, personal investment plays a relevant role in the success of the studies. This comprises efforts that an individual is able to devote to studies, in order not to quit in the face of obstacles.

The concept of personal investment has been identified by Weidman, Twale and Stein (2001) as one of the three elements of socialisation into a professional role, the two remaining elements being advanced knowledge and personal engagement. Personal engagement concerns frequent interactions with university teachers and more experienced doctoral students in scholarly activities such as research and participation at conferences. "The frequency and content of interactions between students and significant others has an impact on the students' integration into the academic community and eventual identification with and commitment to a professional role." (Weidman \& Stein, 2003, 648). Role acquisition can be enhanced by a favourable departmental environment, the socialization of a novice into an effective role adoption, and the "integration of knowledge with professional practice have less to do with the formal structure or explicit goals of a department than with the general climate established by informal contact between faculty and students" (Sherlock \& Morris,1967, cited by Weidman \& Stein, 2003, 644).

What the authors describe is the general process of the student's socialisation into the academic norms and research. However, the study participants' reality was different, as documented by the following quotes.

My doctoral studies were a total absence of any activity related to science and research. (M3) 
I was aware that I didn't have time for my research. There were other responsibilities all the time. (M3)

The doctoral studies represent an important milestone in the life of a student. However, even if the doctoral programme is excellent, it cannot substitute for the lack of engagement of the student in scientific work. The doctoral programme can stimulate the students' interest and can provide a favourable environment so that the student will acquire good foundations for research.

\subsubsection{2}

The Teacher's Role

In addition to acting in the student's role, those doctoral students in the full-time programmes taught at the university performed in the teacher's role as a part of their responsibilities. Being a university teacher was an entirely new role.

It was a radical change. People with whom I lived in dormitories suddenly became my students. All of a sudden, I realized I had to behave. Also, I had to rely on myself. The teachers from my master's studies were gone so I could not count on them. This was a new phase in life. (F2)

For some of the study participants, the role of being a teacher was not a new one. They were novice teachers at a university, but they had teaching practice at primary or secondary schools, and some of them were employed in social care institutions. Employment brought workplace experiences and improved their financial situations. Employment opportunities were used even by the students in the full-time programmes, which indicates that the studies were not demanding and rigorous and did not require a high degree of commitment. Some students perceived doctoral studies as an interesting activity in addition to having a job. The university did not strongly discourage full-time students from taking up employment during term time that might interfere with their studies.

The study participants, who were teaching at primary or secondary schools before starting their doctoral programmes, considered their former employment a temporary job, which they did not want to continue. For them, the doctoral studies were a means to change the employment situation.

The doctoral programme was a path to freedom from teaching at a primary school. It was pretty demanding. I was nervous about noise during breaks, and 
about the impossibility to go to the toilet during classes. A lot of trifling things bothered me. (F1)

I was teaching at a primary school, and I disliked it terribly. I didn't want to abandon learning. I desired to do new things, so I was an awfully unsatisfied teacher, they told me. (F7)

I was teaching a lot. As many as eleven classes per day. Seven classes at school and four at the college. (F2)

Teaching sometimes results in new situations. Study participants reported they frequently substituted for a teacher who was unavailable. The students were dissatisfied by not teaching the subjects of their specialisation. Frequently, they had to teach several disciplines, even those unrelated to their study fields. Sometimes it happened that they were assigned to teach unfamiliar subjects each semester.

I felt that they expected I had to know everything. I was unable to concentrate. Some subjects I taught were entirely unknown to me, they were beyond my field. (F1)

Czech universities are not exceptions to this malpractice. Austin (2002) conducted a study on doctoral students at three American universities to reveal how the knowledge, abilities, and skills relate to the socialization and preparation processes. She interviewed a sample of graduate students in a variety of disciplines, including the humanities and sciences. The data showed a "lack of systematic professional development opportunities, minimal feedback and mentoring from faculty, and few opportunities for guided reflection. Although some students had faculty mentors who guided them carefully through the process, most did not." (Austin, 2002, 7)

The university has a responsibility to provide assistance and support for novice teachers. It should spend large amounts of time dealing with novice teachers' problems or problem situations in which novice teachers are involved. The assistance in teaching competences development should be a component of doctoral programmes, using a number of manners and strategies. Many universities provide such assistance as an integral part of the studies, while others are not interested in improving this. A doctoral graduate, who enters employment at a university, becomes a teacher, even though their field of specialisation is not pedagogy.

The development of teaching competencies should follow these general guidelines:

a) Provision of a course in the theory of university education (a discipline within the system of educational sciences in the Czech Republic). This course should be 
available to students in any doctoral programme, including those who pursue educational sciences. This is because education includes fields beyond teaching, such as social education, special education, therapeutical education, speech therapy, etc.

b) Teaching observation. An offer to observe and analyse classes of experienced university teachers, and possibly also observation of the supervisor's classes. A good practice is if the supervisor presents to the doctoral students his/her system of instruction, lesson plans, classroom management style, instructional practices, etc. In turn, the supervisor should observe classes taught by the doctoral student.

c) Discussions dealing with instructional matters such as dealing with problematic students, uncompleted work, late submission of work, or poor performance.

As the doctoral student is a novice teacher who generally has no teaching experiences prior to enrolment, it is a reasonable strategy to provide the student with a teaching mentor, ideally a supervisor. The mentor's task is to instruct the student how to transform the curriculum into instructionally-relevant teaching practices, how to plan courses, what to do before, during and after each class session, or how to take advantage of available resources.

Doctoral students acquire two dissimilar roles, which should be harmonized: a teacher and a researcher. These roles do not exist in lower education, but in higher education they are the essence of the doctoral student's engagement at a university. A good teacher is one who conducts research and is able to transfer the new knowledge to the classes. The fresh knowledge helps students broaden their horizons in the professional field.

Anderson et al. (2007) examined doctoral students' perceptions of effective university teacher characteristics. The sample consisted of undergraduate and graduate students from various academic majors enrolled in an American research university. Nine characteristics were identified, suggesting that a blend of attributes is required by the university teaching profession. These attributes are listed in decreasing frequencies:

- Professional. Displays behaviours and dispositions deemed exemplary for the teacher's discipline.

- Ethical. Demonstrates consistency in enforcing classroom policies, responds to students' concerns and behaviours, and provides equitable opportunities for student interaction. 
- Student-Centred. Places students in the centre of the learning process, prioritizes instruction in response to student diversity and interests, and possesses strong interpersonal skills.

- Connector. Provides multiple opportunities for student and university teacher interactions within and outside of class.

- Responsive. Provides frequent, timely, and meaningful feedback to students.

- Expert. Demonstrates relevant and current content, connects students' prior knowledge and experience with key components of curricula.

- Transmitter. Imparts critical information clearly and accurately, provides relevant examples, integrates varied communication techniques to foster knowledge acquisition.

- Director. Organizes instructional time efficiently, optimizes resources to create a safe and orderly learning environment.

- Enthusiast. Exhibits passion in delivery of curricula, in particular, and representing the field, in general (Anderson et al., 2007, 292).

The professional received the largest endorsement, with approximately two-thirds (66.1\%) of the sample. This was followed by the ethical quality of the teacher, which nearly one half (i.e., $47.7 \%$ ) of the doctoral students endorsed. The smallest frequencies were of the director and the enthusiast (Anderson, et al. 2007, 292).

As documented, none of the effective university teacher qualities explicitly expressed the application or presentation of research findings in the instruction. However, several endorsed qualities might suggest it: the university teacher "is exemplary for the discipline", "demonstrates relevant and current content" and "imparts critical information" (Anderson, et al. 2007, 299-300).

The roles of a teacher and a researcher at the university are inseparable: they exist in a symbiotic relationship. One supports the other to provide the best opportunity to provide advanced higher education.

\subsubsection{3}

\section{The Researcher's Role}

The study participants anticipated acquiring the researcher's social role as a big challenge. They considered it a primary mission in their studies. However, they also indicated that they needed role models to help them socialize into the researcher's role and find favourable conditions for doing research. 
One of the options of supporting doctoral students' socialisation into a researcher's role is to offer them participation in research teams. A team is a group of people possessing complementary knowledge and skills, which serves to attain a common goal and share the team's responsibility (Katzenbach \& Smith, 1993). According to Schein (1988) and Smith (2003), an efficient team possesses the following characteristics:

- Clear objectives and agreed upon team goals.

- Knowledge and skills needed for achieving the team goals.

- Support and trust.

- Shared responsibility.

- Sound inter-personal relationships.

The interviews showed that only two female and one male study participant took part in the department's research projects. They greatly appreciated this experience, though it caused the prolongation of their doctoral studies.

I worked on my supervisor's research project, which was funded by GA $\check{C} R$ [the state agency providing research grants]. I was in charge of processing questionnaire data and conducting interviews. This research engagement, however, caused the change of my dissertation topic. (F6).

I was engaged in a GA $\check{C} R-$ funded project, and it was an excellent experience. Though this caused the prolongation of my studies, I do not regret it. (M1)

Participation in research teams seems to be an efficient support for doctoral students on their path to become researchers. It is an excellent opportunity for the informal learning of research processes and interpersonal communications. As documented by the first quote, the team experience was linked to the supervisor's research endeavours.

One can become a researcher only if having an opportunity to discuss research matters. I think that a researcher should ponder research researcher components and should have enough time and stimuli for it. And also have the assistance of the supervisor. (M1)

Not all study participants had a chance to participate in a supervisor's or department's research projects. Some doctoral students never join a research team. The following quote documents that such an opportunity appeared, though too late. 
Ifeel like being an apprentice who's learning to conduct research. It's a pity that I am isolated. I might become a researcher in a few years, on the condition that I can accumulate experience, which I have none of right now. My supervisor was not supportive. I am starting to gain practice only now, as I was invited to a small research team. I wander how it will evolve. Sometimes we can't foresee if the path is the right one. (F2)

A team is dynamic system of people who cooperate on common tasks, during which the quality of and the relationships within the team develop. Woodcock (1979) has defined four phases of team development:

- The underdeveloped team. In this team, feelings are avoided, objectives are uncertain, the leader makes most of the decisions.

- The experimenting team. Issues are faced more openly, listening takes place, the group may become temporarily introspective.

- The consolidating team. Personal interaction is established on a co-operative basis, the task is clarified, objectives are approved.

- The mature team. Feelings are open, a range of options is considered, methodical working methods, individuals are flexible, the group recognizes responsibility.

In the above quote, the study participant M1 considered the effective collaboration with a supervisor. If such collaboration would have taken place in a team, it would relate approximately to the second team phase in Woodcock's hierarchy. The second quote (F2) describes the doctoral student participating in a newly-formed team, thus corresponding approximately to the first phase in Woodcock's system.

None of the study participants described their performance in research teams in detail. They provided no specific accounts as to how the work was coordinated, how the tasks were distributed or how the relationships were built. This might indicate a student's weak position in the team, or inadequate understanding of teamwork.

Nobody was born a researcher. The student can only learn research competencies by accomplishing a variety of empirical studies. Working in research teams is a strong stimulus for the development of scholarly potential. The aims of the doctoral programme must be the acquisition of both competencies, doing research and teaching. 


\subsubsection{4}

\section{The University Employee's Role}

After enrolling in the doctoral programme, students become parts of the university organisation, which has its rules and goals. The more accurately the goals are set, the more the individuals are orientated in the institution's performance. This is a prerequisite for attaining the university's goals and a determinant of the university's achievements.

The doctoral student's position within the university system is determined by four major factors:

a) the status of the studies (full-time or part-time),

b) employment in academia at the time of enrolling in the programme,

c) employment outside of academia,

d) unemployment.

In the accounts of the study participants, the following constellations appeared:

- Doctoral students enrolled in the full-time programme, and had no employment in academia during their studies. Being students, they had an opportunity to perceive the university system, workplace climate, teachers' communications, teachers' workloads, etc. After gaining a $\mathrm{PhD}$, they were offered employment at the department of their studies and gradually acquired more complex knowledge of the university system (M3, F5).

- Doctoral students enrolled in the part-time programme while being employed outside academia. During the doctoral studies, they had scarce contacts with the department staff and university administrators. As a result, they acquired little knowledge of the university system and the work of the department (F1, F7).

- Doctoral students were teachers at a university and enrolled in the part-time programme at a different university, where their primary role was that of students, not of university. They were well acquainted with the university system, albeit of a different university (F3, F6).

- Doctoral students were enrolled in the full-time programme, and had no employment. During their studies, they were offered a job at the university. As a result, they switched to the part-time programme. As university employees, they had an excellent opportunity to acquaint themselves with the university system (M1, M2, F4). 
The most intense socialisation into the university system took place in the first and the fourth groups. But, this process was even stronger if the doctoral student remained at the department that provided the doctoral programme. The study participants of the first group confessed that they were overloaded with administrative and organisational tasks at their departments, which distracted them from their studies. However, success in these tasks gave them a good reputation, leading to a job offer at the department. They transferred from the full-time to the part-time programme, and, as a result, they prolonged their studies.

The following quotes show varied forms and intensities of symbiosis of studies and work for the department.

The work at the department was a burden that hampered my studies. I was in charge of administering the admissions and of other tasks, and I desperately tried to catch up on my studies. After two years in the full-time programme, I transferred to the part-time because I was unable to meet the study responsibilities. So I became a department member. (M2)

When coming to the department, they immediately assigned me complex tasks. I had to learn the role of a bureaucrat because I administered the students' projects and also I was performing other tasks. There was little time to study. After a year I moved to the part-time programme. My studies extended to seven years but I do not regret it. I like the work at the department and I'm in close contact with colleagues, and I had time to ponder my project. (M1)

I completed the doctoral programme in seven years. I was constantly catching up on my studies, and the colleagues helped me to discuss my problems (F4).

As explained by the study participants, their employment at the university shaped their professional skills in these domains:

- organisational/administrative,

- interpersonal communication,

- research design.

Concerning relationships of department members with the doctoral student, the following roles were identified:

- task assigners,

- project co-administrator,

- project co-researcher,

- professional discussion partner. 
While working in research teams, the doctoral students acquired varied positions and took on new identities. A social position is a status that has a social value. Individuals can hold many positions in teams, which vary according to the responsibilities and the professional standing. Additional factors are age and psychosocial development. Some positions are taken spontaneously (e.g., gender, positions within the family system), others are acquired (e.g., by studies, workplace experience, community or political activities). Every position is linked to a role characterized by behavioural patterns, rights and responsibilites (Schnitzerová \& Kubáni, 1992; Flešková, 2007). Acquiring these patterns, rights and responsibilities were the chief tasks of the study participants after joining a research project team.

\subsubsection{5}

\section{The University Administrator's Role}

Three out of ten study participants acquired major positions within the university system. While pursuing their doctoral studies, two became vice-deans and one was a department head. Though being young (none of them was over age 35), they were assigned managerial positions because their superiors believed in their organisational abilities and skills. They also had high professional ambitions and strong career goals. In the work psychology domain, such young administrators are labelled "kinder managers".

New assignments came, so I became a vice-dean. We had to prepare documents for the accreditation process, so my work was to distribute tasks, check them and organize things. (M2)

As leaders, they were involved in many aspects of the department/university operations. They desired to bring a fresh style into their administration, but they had almost no experience in working on complex administrative tasks. They had to make decisions, among other things, on curricular, personnel and financial matters, admissions, and quality assurance. This work proved exhausting. As a consequence, their motivation declined. They also became disillusioned about relationships with the department/university staff. This led to the decision to abandon the administrative position and become regular department members - with feelings of disappointment and embitterment.

I'm tired of power relations, and of solving matters that I consider useless. After I quit the vice-dean position I will immerse myself into the science. If the situation 
were different, I could have managed to bring all these things into consonance. But I reject working for these people. (M2)

I did a variety of fragmented things, which created no outcomes. (F3)

However, they were not only unsuccessful in doing the administrative tasks. They also failed in acting as leaders in the organisation. While their administrative collapse may be attributed to a lack of experience in organisational management, their leadership failure was caused by a lack of leadership skills. Their conflicts arose from their inability to persuade others of the meaningfulness of the work. These others were not a close group of people but individuals from a variety of fields and departments, who followed their own agendas and goals. The youth enthusiasm did not help; disillusionment and despair followed. It was a leadership failure (Brooks, 2003), the core of which was an inability to distinguish (and perform) managerial and leadership roles. These are not the same thing. The manager's job is to plan, organize and coordinate, while the leader's job is to inspire and motivate. Leadership is defined as the potential to influence and drive group efforts towards the accomplishment of goals. Metaphorically, leadership is the heart of an organisation. The study participants, who were assigned administrator positions, had deficits in engaging and inspiring the staff also because they lacked appropriate interactive and persuasive skills. Such skills accumulate within the career development and professional socialisation, while the individual is in wide-ranging contact with the professional staff, understands its values and wishes, and uses it in performing the leadership role.

The study demonstrates the importance of forming unambiguous managerial rules and norms at the institution. It is imperative that a university manager and leader possess adequate experience to understand the web of relations and bonds, which are an integral part of the university system.

\subsection{2}

\section{A Key Person as a Researcher's Model}

In the decision to become a researcher, some of the study participants were inspired by key persons. A key person is an individual who affects the development of the study participant by having a strong influence on professional attitudes and career decisions (Kelchtermans \& Vandenberghe, 1994). The study participants' key persons were as follows: 
- A family member who, serving as a role model, accomplished the inter-generational transfer of the profession.

My grandfather was on the scientific board, so I used to listen to his accounts at home. He explained how they discussed research, which matters they approved and which not, and what he could do if not approved. He still tells these stories, and he is 91 now. (F1)

- An inspiring university teacher.

I met with interesting teachers. I haven't had such an experience before. I hold books in my hands written by people who then taught me. (F7)

- The doctoral student's supervisor.

I have had a nice relationship with the professor. We became fond of each other. He used to give me advice that helped me in deciding what to do next. (M3)

- A department colleague.

Two colleagues from the department had an impact on me. I started to travel to trainings with them, and I realized how important it was. This made my decision. I said "This is meaningful, and I want to do it." (F7)

I went to a lecture of the associate professor, a colleague at the department. I was enchanted, so I embarked on this topic. I used to frequently discuss matters with him. (M2)

- A friend.

I have a friend with whom I go to a pub. He is an Italian and does not reside here all the time. When he is here, we discuss sports sociology, the topic that captivated me. I am happy we met at that pub. Since that time, we have discussed many matters. (M1)

Meeting a key person on the route to becoming a researcher is a strong stimulus that encourages and excites people to professional actions. Role models and inspiring partners have the potentials to shape or accelerate the professional development of individuals by helping them to make decisions, set realistic goals and find means to achieve them. 


\section{2 .3}

\section{Integration into the Professional Community}

In addition to inspiring role models and enjoying a favourable family environment, the doctoral students benefitted from interaction with the university's professional community. This community became an important part of the doctoral students' lives. The individuals identified with the university milieu and acquired behaviour patterns that are essential for academia. Though being students, they became familiar with the roles that the university teachers perform.

A chance to become university teachers after gaining a $\mathrm{PhD}$ was a strong motivational factor for the study participants. It influenced their attitudes and workplace strategies. Their lives in academia were patterned by these relationships:

- Internalisation. The doctoral student considered the departmental goals meaningful and wished to contribute to the department's good standing.

I am expected to teach well, but what I value more is research because it brings a surplus value. That's why I want to stay here. (M1)

- Subordination. The doctoral student became a university employee and had to respect its rules and norms.

I can't express my opinions [openly]. My intention is to remain here, so I have to do what they expect of me. (F5)

- Identification. The doctoral student identified with the university teacher's role, albeit not because of the employment but because he/she wanted build a reputation in the professional community. Working at a department was a way to accomplish this personal goal.

Like other people here, I want to write a monograph to prove my potentials in the field. (M2)

The most common manner of presenting research findings is a publication in a scientific journal. However, rather than publishing, the study participants emphasized participation at conferences and seminars as a way of presenting research findings. Czech universities do not strongly support such participation. A paper presented at a conference does not bring points like a journal article. The study participants 
considered conference participation to be an excellent tool for meeting with colleagues and a way to integrate into the professional community.

Currently, they make virtual people from us. Unfortunately, we have to work in the virtual academic environment. (M3)

I wish we were obliged to attend conferences. I am very thankful I could participate because it forced me to cultivate my oral and written communications. I learned to manage stress. (F5)

Another manner for integration into the professional community is cooperation with colleagues.

The joint work helps me. We frequently work jointly, sit in an office, speculate, write... (M3)

I see how it enriches me if I hear an opinion of someone whom I believe. (F2)

Interestingly, in order to avoid criticism or failure, the study participants preferred discussions with peers rather than with university teachers. Conversely, they gained support and understanding in discussions with peers.

It is worth working in teams. I need to talk with someone who is of the same age and has similar concerns. I have to learn to find solutions. (F1)

The study participants were interested to know how peers perceived them. Working in peer teams was a good opportunity to see this. Peer learning is a reciprocal activity in which all participants interact, share knowledge and opinions. If differing viewpoints appear, they are negotiated. Peer learning supports intellectual development and promotes the development of interpersonal skills: being friendly, listening to others, and speaking positively.

Each Thursday we organized scientific circles. I was always looking forward to participation in these. They were either formal or informal. Then we went to have a beer. (F1)

The study participants started relationships with peers and built their professional foundation, which later resulted in a systemic professional cooperation. This was the first phase in developing their professional careers and extending 
their professional networks. The peers provided mutual support in problematic situations. The cooperation increased self-esteem and self-confidence, which in turn reinforced their self-evaluation and shaped personal constructs.

If doctoral students found firm ground among peers, it facilitated their entrance into the professional community. This was a good route to becoming a respected member of the community.

\section{3}

\section{Specifying the Dissertation Topic}

The doctoral studies are completed by a dissertation defence, which is meant to prove an individual's scientific capabilities. It is therefore of great importance to take the dissertation work seriously during the entire duration of the studies. Working on dissertation research should be the core activity of doctoral students. However, circumstances at the department, in the family or other events often prevented them from performing research intensively.

At the beginning of studies, the doctoral student selects a dissertation topic (at Czech universities, typically displayed on the department's website) and is assigned a supervisor. The student and the supervisor. meet to discuss the research design. As a result of a series of consultations, this design becomes more sophisticated and complex.

However, even though the dissertation topic was chosen and the doctoral student began to work on it, it occasionally happened that the dissertation topic was changed. A stimulus might come from the professional literature.

I plunged into the literature, and found a new idea. Then I consulted it, and a new topic was born. (F1)

I sunk into books, but I didn't go any further. So I considered an alternative approach and then also a topic change. I had to rely on my research route. My supervisor was mystifying and didn't help me at all. (F2)

The doctoral student's integration into the department's research team was another important circumstance affecting a dissertation topic change. This happened if the doctoral student was enrolled in the part-time programme, and the student's department started a new project. During the project work, the student experimented with a number of research methods, which resulted in changing the dissertation 
topic. The experience with new research methods was so strong that the doctoral students could not resist the change, though it happened as late as in the middle of the doctoral studies.

When I enrolled in the doctoral programme I had a completely different topic. In fact, it was an extension of my master's thesis. But the department ran a Czech Science Foundation project and I was required to join. So I worked out a new topic right in the middle of my studies. (F5)

The original dissertation topic of the participant was linked to previous research. The new topic was adopted, but the conception of the new research was not yet clear. It was surprisingly common that a dissertation topic was adjusted during the work on the dissertation, but the student's understanding of the research was vague. Pitcher and Åkerlind $(2009,42)$ identify this as a more general problem: "The differences in conceptions of research, either between groups of academics or between academics and non-academic staff or students, can cause misunderstandings that prejudice the communication between the people involved. It is the conception of research that is important in the communication process."

But, also a mis-match between the supervisor's and the student's conceptions of the study may lead to problems with the supervisor/student relationship and thus to the student having problems with the study and/or not completing the PhD. If the supervisors are aware of their students' conceptions of the study, then steps can be taken to reduce the risk of complications arising from such a mis-match.

Study participants' inexperience with the study designs caused confusion. This peaked in the second year of their studies, referred to by them as the halftime. Typically, they changed from quantitative to qualitative methodologies or vice versa. They hesitated to choose among methodological approaches such as a case study, phenomenology, interpretivism, experimental research, ethnography, etc.

I found out that no statistics can solve what I wanted to investigate. Therefore, I chose a qualitative research methodology. (M2)

If a study participant joined the supervisor's research team, the participant had the chance to increase their methodological competence within the shared research. Working on a joint project with specific methods and research tools often inspired the young researcher, which, as a result, might have changed the methodology.

I learned to administer questionnaires, conduct interviews and analyse the data, which broadened my horizons. (F6) 
However, working on a joint research project has pros and cons. On the one hand, the student extends their knowledge, but on the other hand, time needed for personal research is lost. This creates the threat of a prolongation of the doctoral studies, as was the case with study participant F5. Instead of completing her studies in four years, which is standard at Czech universities, she ended her doctoral programme in seven years. This was caused not by being overloaded with research but with organisational tasks.

In the project, I had to do awfully many administrative and organisational assignments, so I had little time left for my dissertation. (F6)

Having enough time for dissertation research should be a requirement of the doctoral studies. Work in a joint research project should rather be an additional and not a dominating activity. It should not affect the course and the pace of the studies.

Czech universities provide funds to support student independent research projects. In addition to gaining new scientific knowledge, these projects aim to support the development of student research competences. If such projects are associated with the dissertation topic, they can accelerate the dissertation research. The projects provide funds to pay for costs associated with field investigation, participation in conferences and travel. By the rules, a university teacher must participate in such a project and assist the young researcher.

Another funding option for doctoral students is the so-called Junior Czech Science Foundation projects provided by the Czech Ministry of Education. This is an entirely student endeavour, and participation of a university instructor is not recommended. This does not mean that such projects are single-person activities. An ambitious student may constitute a small team to conduct the research.

The effort to define the dissertation topic and constitute the research design is a manifestation of the independence of a doctoral student. These activities provide opportunities for learning to act independently and to be responsible for one's decisions. Constituting the research project and accomplishing it is considered an important milestone of a researcher's development. 


\section{4 \\ Conditions for the Study}

In constituting the study design and conducting the investigation, two conditions are of primary importance: the doctoral student's communication with the supervisor and the explicit and implicit university rules and norms.

\subsection{1}

\section{The Supervisor}

The supervisor is a pillar of the doctoral student's studies. The student's success is greatly affected by the nature of the supervision and the quality of communication between the two. When students work closely with their supervisors and their collaboration is efficient, they can receive guidance in every phase of the dissertation process: planning, drafting, writing and finishing a dissertation. With respect to the research, the supervisor has a key role in planning and managing the students' investigations. With respect to the courses, the supervisor helps in creating a reasonable schedule of courses and other required activities of the student.

The supervisor consults with the student on the student's academic progress and research. When necessary, the supervisor assists the student in gaining access to facilities or research materials. The frequency of consultations varies according to the discipline, stage of work, nature of the project, independence of the student, full- or part-time status, and the supervising style.

The supervising style is a relatively-stable characteristic, with typical features of conduct. By virtue, there are many supervising styles, each being determined by the supervisor's personality and experiences in the field of specialisation. G. Davis (2004) has identified five supervising styles:

1. Strong master/apprentice style. In this style, the supervisor is the master and the student is an apprentice on problems selected by the master. The student is strongly guided and may not develop an ability to conduct research independently.

2. Collegial master/apprentice style. This is a less-restricted style than strong master/apprentice. It puts more responsibility on the student, but the student's dissertation must fit within domain of the supervisor.

3. Collegial development style. In this style there is a joint learning experience. Both the student and the supervisor. learn the details of the dissertation research area. 
4. Guidance and suggestion style. The supervisor provides adequate general guidance, but the mentoring and advice lack detail.

5. Passive hands-off style. The supervisor provides some suggestions, but the responsibility is almost entirely with the student.

Each style has pros and cons, depending on the student and the problems being studied. The styles rarely exist in pure forms; they are not discrete categories and most of the supervisors have characteristics from more than one supervising style.

Based on this taxonomy, three supervising styles have been identified in the descriptions provided by the study participants:

- Collegial development style (4 study participants).

- Strong master/apprentice style (2 study participants).

- Passive hands-off style (4 study participants).

The doctoral students with the collegial development style supervision managed to work independently, but were well supported by the supervisor to think about the study, consider alternatives and judge different perspectives. In discussions about their dissertation, they developed their viewpoints. They also started to publish under the guidance of the supervisor.

I've had a nice relationship with my supervisor... He told me he liked the way I worked. I didn't insist on consulting with him, I only brought him my texts, we discussed them, and then sent them to the editor. Then a chance appeared to write a book. I used this chance. (M1)

A different picture is provided by the doctoral students who were highly dependent on their supervisors (the strong master/apprentice style). In the second year of their studies, due to their participation in their supervisor's project, they changed the topic of their dissertations. Later, they commented on it as a comfortable way of survival. They were weakly integrated into the professional community. The supervisor did not guide them to learn more open and independent study approaches and did not provide critical feedback or encouragement on their work.

My supervisor was a big personality. He was strict, rigorous. He didn't allow me to change my topic. After the completion of my studies, I didn't remain at this workplace. I transferred to a different department, where I had to learn a lot of new things, which I didn't need before. Also, I had to find my own "cup of tea". (M3) 
Some supervisors used the passive, hands-off style. The mutual communication was sporadic. Over some periods of time, the students were unable to meet them on a set schedule, or even to meet them at all. These supervisors were employed parttime at the doctoral student's university, or had a sabbatical, or were on long-term leave. The doctoral students had to jump hurdles to independently make progress.

I had little opportunity to meet with my supervisor because she was on maternity leave. But she was an emphatic person. She let me find my own way until I saw I was wrong. She did not force me to go her route. I found this satisfactory. (F2)

In addition to consulting with supervisors, the study participants also sought other people to communicate with on professional topics. These were colleagues from the department or from other institutions whom they believed were important persons in the field.

I used to travel to Prague and Brno where I was looking for specialists. I also attended courses that helped me orientate myself in my topic. (F6)

The data show that there is a relationship between the supervisor's passive handsoff style and the study participant's search for someone to substitute for the supervisor. Faced with a passive supervisor, in order to survive the student searched for support from someone else.

I sought consultations elsewhere because my supervisor was on maternity leave. She didn't have time for me. (F2)

In order to make sure I took the right road, I contacted specialists at other universities. My topic was born, stabilized and crystallized in interactions with relevant people. (F4)

But the study participants described also unfavourable experiences with specialists whom they consulted. They frequently presented different perspectives, and seemingly did not help the young people. However, these consultations should not be considered hopeless. The doctoral students had to compare and contrast standpoints and strategies, which was good training in research decision making.

There were people whom I considered useless to consult with. For instance, when I saw that they were not interested in my topic, they found it unimportant, or they had a completely different attitude. (M2) 
These discussions with professionals increased after the study participants became university teachers. They capitalized on the networks into which they were integrated during their doctoral studies. These relationships expanded their resources, informed them about potential opportunities and collaborations, helped them answer questions, discuss the current research topics, learn from other people's failures or experiences, and establish themselves as experts in the field (see chapter 4).

\subsection{2 \\ University Rules}

While the study participants were at the university, they had to abide by the institution's rules and norms, established in order to attain its objectives in an orderly and efficient manner. Universities have a variety of rules and norms: statutes, bylaws, administrative codes, rules of conduct, etc. Their purpose is not only to protect employees but to enhance their performance and professional development. Other laws are state-wide, for instance, the labour code that is applicable to any institution.

In addition to the formal norms, each institution establishes informal norms: traditions, rituals, narrations, and metaphors. They constitute the system of verbal or visual symbols that create the institutional culture (Světlík, 1996). Some of the symbols bear a meaning that is only understandable by the institution's employees, not outsiders.

The study participants described several rules that they had to respect. The first rule was to be present at the workplace. The doctoral students were expected to follow a certain schedule. It appeared, however, that this rule was not obeyed, or even checked.

There was a rule of showing up and sitting in an office for three days a week. Somebody was expected to check the presence, but he refused. This freedom was pleasing. (F2)

Most of the participants with full-time status were surprised by the autonomy they now had, which they did not have during their master's studies. However, this autonomy proved to be a disadvantage in the final phase of dissertation writing (see chapter 3.5).

Another rule was taking part in administrative and organizational assignments at the department. They assisted in the enrolment process, reviewed students' records, organized seminars and meetings or took care of visitors. 
The administrative work to substitute for someone was demanding. I was unable to get accustomed to it. I'm a person who has my own assumptions of what to do and how to do it, especially in administrative tasks. It took much time to defend my conception of work. (M1)

Administrative assignments belong among normal departmental chores. But the doctoral students also substituted the classes of supervisors or department heads, if they were unavailable for personal leave or other reasons.

I frequently substituted my supervisor's teaching. I taught his courses, which were different from mine. Simply, I was a substitute. Then I loaded grades into the information system. This took much time. (F2)

The doctoral students were unable to reject such tasks because they had little power. Their supervisors should have intervened, because they were responsible for guiding the doctoral student's studies and research. But the supervisors themselves were occasionally substituted for, so they did not do what they were expected to do.

Four of the study participants negotiated their administrative assignments with the department head. The heads promised the students a job at the department if they would engage in administrative tasks during their doctoral studies. The students accepted the deal, and transferred from full-time to the part-time status. They "paid" for a secure job by a studies prolongation.

I studied in the full-time programme during the first three years, and then I switched to the part-time. This was because I administered an innovation project right from the beginning of my studies, I was overloaded with administrative work, I organized drama education courses, etc. These were the reasons to switch to part-time. (F4)

When I wanted to manage all the work at the department, I faced the simple fact that I couldn't keep up. Then I was offered to transfer to the part-time programme and take a job at the department. I don't regret it. My topic has matured and I gained confidence to finish it successfully. (M1)

The duration of the studies was altered for the job offer. The study completion was postponed by two or three years, but the student possessed a job, a good opportunity to start a professional career at a university. In addition, the prolongation of studies generated more time for dissertation writing. 
These jobs were offered to those doctoral students who conformed to the rules of the organisation. It is difficult to judge whether their conformity was a sheer pragmatic matter or their decision was based on more profound reasons, such as intrinsic motivation. The students' accounts indicate the former. Nevertheless, the decision paved the way for the professional careers of the young individuals in academia (see section 4 ).

\section{5}

\section{Finalising the Dissertation}

The study participants labelled the final stage of their studies as "hard", "stressful", and "exhausting". The factors that helped them relieve the burdens were family support and assistance from the supervisor and colleagues. A chance to be offered a job after the completion of their studies motivated them to concentrate their efforts in the final phase of their studies.

\subsection{1}

\section{Family Support}

Family encouragement represented a strong impetus to complete the doctoral studies on time. As the data show, the strongest encouragement came from parents and grandparents.

My parents were very proud of me, and I wanted to repay them for their empathy. (F2)

Initially, my granddad didn't believe I could make it. But then he was proud that I completed my doctorate. It was for this reason I wished to defend my dissertation as early as possible. (F1)

The first quote represents the family reciprocity phenomenon. The family's unwritten contract says, you have to pay back for what you have received. Children were expected to return the parents' support because it was considered decent and polite. It was a repayment of a liability to the close family.

The second quote shows the liability of credibility demonstration by the offspring. The granddaughter showed her efforts to her grandfather so that her competences would be recognized. Credibility is a reliance on an ability or 
a personality characteristic, which supports honour and proves that the person is worthy of respect and esteem.

Some of the study participants have already established their own families. They performed the roles of spouses and parents.

The chief motivation to complete and submit my dissertation was my newborn child. I wanted to have it done. I had a job at the department, and a PhD was a path to a promotion and a salary increase. (M2)

This doctoral student searched for a stable job that would bring financial stability to the family. Such stability is an important motivating factor in adaptation to employment. Stability also brings balance, enabling stability development. For the study participants, stability brought emotional and social equilibrium between the employment and family.

This finding is similar to that Jaraim and Kahl (2012), who analysed the support environments of thirty-one American doctoral students ages 29-63. The participants answered online open questions related to supporting or hampering factors in the completion of their doctoral studies. The strongest supporting factor was family: spouses, children and parents. The strongest encouragement was provided by spouses. Family rendered emotional and financial assistance.

The study participants only mentioned family emotional support. Family encouraged their self-confidence and self-esteem, and shared affection and love. Though financial assistance was not mentioned in the participants' accounts, it could have been provided because the young individuals lacked finances to establish and run their households.

\subsection{2}

\section{Support by the Supervisor and Colleagues}

In the final phase of dissertation writing, the frequency of the doctoral students' contacts with supervisors increased. In addition to professional assistance, supervisors provided emotional support. In a sense, the latter was more important than the former because it constituted an emotive buttress in finishing the programme.

I had finished the investigation, but I had no strength to write. At this point, my supervisor helped. He told me I was not supposed to write a "life opus", I have time to do it in the rest of my career. He insisted I stopped contemplating and start finalizing. I took his advice. (F4) 
I felt my dissertation missed something. Then, my supervisor told me it was ready for submission, ordered that I have it bound, and that other matters would be solved after the defence. (F6)

I got lost in the lines and chapters. Then my supervisor summoned me to his office to discuss matters. He encouraged me, and this helped in concentrating my efforts to finalize and submit the dissertation. (F7)

In these cases, the supervisors demonstrated emotional and social intelligence, recognising the doctoral students' problems, and acted supportingly. Generally, understanding the doctoral students' fears was a major factor in providing them assistance in the final phase of the doctoral studies. Though technical issues, like the dissertation format, were also discussed, this was not the major topic of feedback.

However, some supervisors provided negative help or anti-help by offering no assistance at all, though the students strongly expected it. The reasons were diverse: They preferred other professional issues, had family problems, were on maternity leave, or left the university.

When I needed her extensive assistance, my supervisor didn't have time. So I had to rely on my colleagues' help. (F2)

This quote suggests that the passive, hands-off supervision style not only applies for the initial and middle periods of the doctorate but also for the final phase, in which it is most harmful. Unanswered e-mails or the unannounced absence of the supervisor increased anxiety and demoralised the student. The support provided by colleagues, mentioned by the study participant, was a first-aid action. It was not a constant guidance throughout the research and writing, and it concerned only the final phase of the dissertation writing. Still it was precious.

\subsection{3}

\section{A PhD as a Job Prerequisite}

As mentioned, half of the study participants were offered a job at a university during their studies. They accepted the offer and became university teachers, while continuing their studies. This decision, however, prolonged the time it took to earn a doctorate. 
This prolongation of the studies required a transfer from full-time to part-time status. The time to receive a doctorate was extended from 4 to 5-7 years.

The final phase of the doctoral studies was referred to by the study participants as a race. The time was set to gain a $\mathrm{PhD}$ as a condition to attain a job at the university. They did their best to keep to the deadline.

At Czech universities, a PhD is considered a minimum requirement for teaching. When applying for accreditation of the study programmes, the accreditation board checks whether this requirement is met. Occasionally, the candidate is placed on probation until the degree is gained.

I needed a job at a university. I knew that nobody would employ me in my discipline without a PhD. So I raced to finalize my dissertation because the deadline was approaching. (M3)

I was promised to extend my employment contract on the condition that I defend the dissertation on a set date. I desired to get the job at the department, I enjoyed working there. (M1)

Some of the study participants needed a doctorate to leave a job that they disliked. They were teaching at primary or secondary schools, were dissatisfied, and had ambitions to pursue an academic career at a university. A doctorate was a criterion to apply for a job.

I wanted to gain the doctorate as quickly as possible in order to get a job at a university. Primary school was only a temporary solution, I was sure. (F1)

I wished to teach at a university very much. I knew I had to write that dissertation, or I was lost. (F2)

I had a powerful motive to leave that primary school and use my abilities for what I desired, at last. (F5)

The study participants believed they had potentials to educate students at a university. The desire to "achieve" or to "get somewhere" was a strong motive to leave their current jobs.

I knew I had the ability. At [primary] school they kept telling me "You are good at teaching, go to a university and share your knowledge with the students." (F7) 
Ambitions, supported by colleagues, drove the students to complete the doctoral studies on time and enabled them to start their academic careers. Ambitions are important, especially when the statistics say that a great majority of candidates do not complete their doctoral studies. Employment motivation is a strong factor shaping the future plans of the students.

Looking again at the interview data, the following components of their studies emerged in their accounts:

1. specifying the dissertation topic,

2. establishing a relationship with their supervisor,

3. orientation in the professional community,

4. establishing academic and professional contacts,

5. understanding the university rules and norms,

6. cooperating with university teachers and peers,

7. support from family and friends.

Importantly, not all the components and phases in the doctoral study and research phases were described by the study participants. Among others, they omitted passing the courses, working in the field to get empirical data, processing the data, establishing the content structure of the dissertation, and preparing a strategy for the dissertation defence. This does not mean that these elements were unimportant; they simply did not surface in the interviews.

Chapter three is based on the study participants' accounts on their doctoral studies in the field of pedagogy. These accounts reflect their personal attitudes and values and therefore cannot be considered an objective picture of doctoral studies. Furthermore, the chapter was based on personal narrations of ten people only and cannot be generalised to doctoral programmes in Czech universities at large. This is not the purpose of the book. The reader who is interested in an in-depth report on the monitoring of doctoral programmes at Charles University in Prague, the largest university in the Czech Republic, can consult the work of Mareš and Ježek (2013).

After completion of the studies, the study participants started their academic and occupational careers at universities. Chapter four describes this period of their lives in full. It portrays their journeys through workplace adaptation, social identification and integration into the university culture. 



\section{AFTER COMPLETION OF DOCTORAL STUDIES}

Joy accompanied the completion of the tiresome doctoral study phase. Graduation brought only a short-lived feeling of liberation. Suddenly, new opportunities and tasks appeared. Young people needed to determine which professional route to follow and how to use their newly-earned qualification.

In harmony with Carl Rogers's philosophy (1951) almost every person has an idea of what they want to be and become. Rogers described it as an ideal self. The closer the ideal self is to the real self, the more satisfied and happy the person. All research participants expressed strong conviction about their abilities, which are valued and necessary for working at the university level.

They all desired to work there. This aspiration caused a "sprint" through the final phase of doctoral studies, to complete it as quickly as possible in order to achieve their goals - earning a PhD. This degree was viewed as an entry ticket to a professional career at the university level. The influential factor was self-reflection in relation to professional needs, a driving force for most doctoral students.

I know I belong at the university. In school they told me, Go teach at the university, the students need your knowledge (F7)

I wanted to teach at the university and I knew it as early as in the second year of my master's programme. I took notes while learning with the intention of using them once I began teaching. I was sure I belonged at a university (F1)

Concerning professional needs, the participants can be divided into two groups. The first group is represented by those who already had university experiences, albeit not linked to a doctoral position. At a certain point during their doctoral 
studies, they were offered a job at the university - and they accepted it. This affected the form of their doctoral studies. They transferred from full-time to part-time, thus starting their university teaching careers before the completion of their studies. This forced them to quickly adapt to the workplace, which they knew as students.

I wanted to stay at the department, I empathised with them and I enjoyed the work. So I accepted the offer of the department and transferred from full-time to part-time study. (M1)

The second group is represented by those participants who entered the university workplace after completion of the doctoral programme. Previously, they had taught at primary or secondary schools or were employed in other educational facilities. For them, the university job was the fulfilment of higher professional aspirations.

A huge motive was to earn a PhD so that I could go to teach at the university. (F1)

It might be assumed that this group would adapt quicker to the university level because they had previous teaching experience. However, the data did not prove this assumption. Both groups of participants had problems adapting to the workplace. The nature of the problems somewhat differed between the two groups, and it did not concern instruction. The problems were related to the matters of the faculty, department, institute, or cooperation with colleagues. Adaptation to the role of a researcher was another source of problems.

The division of the participants into two groups is significant because there are large differences in two characteristics:

- The position from which they entered the academic environment

- The extent of the possessed knowledge about the university

While the acceptance by colleagues was smooth and spontaneous in the first group, it was not in the second group. The participants of the second group had to learn what their employment position included. Both entry positions had their merits and drawbacks.

Participants of the first group became acquainted with the new workplace during their doctoral studies. Therefore, they felt "at home" there. They also could adopt the style of social loafing. Latané (1979) defined this style as a decrease in personal exertion while acting as part of a team. This style favours conflict avoidance and 
collaboration. One of the features of social loafing is "not standing out". This can be documented by the following interview excerpt:

I did not have conflicts with anyone, this is why I was accepted to the department. The department needed a person with an earned $P h D$, and I had had no controversies with anyone. I did not team up with any person. I took a no-problem strategy. (F5)

However, Harkin and Jackson (1985) demonstrated that social loafing appears also if the work of a person who is anonymously connected with the success of the team. This tendency was indicated in the previous quotation - the person with a PhD degree will bring profit to the department, therefore it is worth having them there. For instance, the person brings "points for publications", which is a benefit for the department. ${ }^{2}$ The department members can socially loaf in writing papers and books. On the other hand, being hired provides security and income.

None of the study participants was given a postdoc, a position generally conceived as a waiting line or a probationary status for a permanent teaching position (Recotillet, 2007; Stephan \& Ma, 2005). The study participants were employed as university teachers without receiving any assistance, support or special provisions for their gradual transfer into university teaching life.

The situation in Czech universities is in contrast to other countries. For instance, Dawson (2007) reports that the number of postdocs who entered the position upon completion of their doctoral studies has been increasing worldwide. For instance, in the United States, academic jobs have increased by $0.8 \%$ in the last decade. However, the number of postdoctoral positions rose by $3 \%$.

Some universities do not leave a postdoc unsupported, but provide professional guidance. For instance, the University of Alabama offers a postdoc programme that provides knowledge about planning and conducting research, training in communication skills and writing applications for grants, as well as teaching competences. This postdoctoral experience gives a young researcher the opportunity for intellectual growth and the development of independent credentials that permit a transition to permanent employment, whether in academia, industry or government (Lorden \& Matalon, 2002, p. 49). A similar example of postdoctoral support is documented by Scaffidi and Berman (2011).

In the Czech Republic, J. Mareš (2013b) proposed a programme of support for postdocs. He stated that there are insufficient postdoctoral positions available

2 Publications of Czech university teachers are assigned points, which are the criteria for evaluation of the person, the department and the university. Points also serve as one of the criteria for subsidising the university by the government. 
especially in the field of pedagogy, and if there are such positions, they are linked to projects financed by grants. Previously in the Czech Republic, there were largescale projects that endorsed the creation or merging of research teams. A kind of substitution for them were projects called "Education for Competitiveness". However, these were innovation-oriented rather than research-oriented. In 2015, operational programmes for the support of science, research and education (OPVV) were launched. Time will show how successful these programmes are.

Although the importance of postdoc training for the development of younger generations of researchers is emphasized, opinions are divided over its real benefit for the university and ultimately for the national scientific base. Occasionally, it seems as if universities offer postdoctoral positions solely for the sake of financial profit rather than for scientific benefits. A postdoctoral position linked to a project is subsidised for its duration. Horta (2009, p. 690) has noted that substantial sums of money are provided, mostly by public sources, to sponsor post-doc fellowships. Because postdoctoral positions are linked to research projects, as soon as the project is finished, the postdoctoral position expires. Thus, a postdoctoral position does not guarantee a job for a researcher.

A lack of postdoctoral positions left this study's research participants without a postdoctoral stage in their careers.

Initially, I was interested to get a postdoc position, but I did not find any. I wanted to learn and develop my expertise, but this was not possible. (M3)

Instead, they entered the authentic academic environment directly, which resulted in favourable as well as unfavourable situations to which they had to adapt.

\section{1}

\section{Occupational Adaptation}

In principle, a new job requires three forms of cultural adaptation: workplace, social, and institutional.

Concerning workplace adaptation, a PhD graduate copes with the tasks of the particular job. The study participants expressed fears about their abilities to adapt to the workplace. 
I wanted a job at a university, but I did not assume what I would have to cope with. (F1)

University teachers must wear two hats, those of a researcher/scholar and a teacher. It is assumed that a PhD graduate can wear both interchangeably. Concerning the role of a researcher, the student earned a PhD and is thus expected to be well prepared to perform academic research. However, doctoral students have generally conducted only their own dissertation research and have little to no experience working in teams, while in the workplace they are expected to manage new research projects and participate in large team projects. As one participant reported,

I have been working as a university teacher for two years, but I have not done real research yet. (M2)

In the course of doctoral studies, only one study participant served as a member of a research team. Moreover, Czech universities do not have a position of a mentor/ leader who, in addition to leading a research team, would advise young researchers about research opportunities within the university, the country or abroad.

Many universities have developed strategies of adaptation for novice university teachers. A good example is the University of Utah at Towson, which assigns an experienced colleague to help integrate a new member into the department. First, the department head nominates two experienced colleagues to act as mentors (usually one has a broader field of specialisation, the other one a more narrow field). The young teacher selects one of them. Adaptation takes place through periodic consultations; the frequency of consultations depends on the level of knowledge and skills of the novice teacher. As the University of Utah is a research university, knowledge of research methodology is a natural component of the programme. Thus, the programme combines the preparation for teaching and research (http:// research.utah.edu/mentoring/department-programs/psychology.php).

In their accounts, the study participants described the role of a teacher and administrator rather than that of a researcher.

The department lacked a teacher specializing in sociological disciplines. Gradually, other tasks began to accumulate. Workplace duties, paperwork for an accreditation procedure, teaching students, etc. It helped me much to grow. But the research was neglected. For the most part, I was teaching. (M2) 
Teacher training did not take place during the doctoral study. In this study, I interviewed graduates of a PhD programme in pedagogy who were assumed to have no problems with instruction. But in reality, this degree does not ensure that a PhD graduate will teach well at the bachelor's or master's levels. In the past, Czech universities offered courses in university instruction for novice teachers, but now such preparation is rare.

A good example of support provided to novice teachers are programmes aimed at the development of their instructional competencies. Finland serves as a good model. Rather than providing advice to beginning university teachers, Finnish universities offer complex training. As Murtonen and Lappalainen (2013) note

In addition to shorter courses, almost all universities started to offer longer, from half to one-year duration courses, valued approximately 10 current ECTS. In the beginning of the 2000s, this activity was stabilized. During the 2000s, university pedagogical courses became an established practice, and the variety of offered courses and extent in ECTS expanded. In the beginning of the 2010s, the biggest Finnish universities are offering the whole 60 ECTS package of a teacher's pedagogical education, the same that is required on other education levels in Finland.

For instance, at the University of Turku, the educational package contains courses like foundations of university pedagogy, teaching and learning environment, social and cultural aspects of education at the university, theory and practice of instruction and administration and development of higher education.

Japanese universities provide novice teachers with a similar training programme. However, in this country the driving force is external pressure. The emphasis is on increasing university education quality in a competitive environment. Since 1990, the state universities have been establishing educational centres, which are responsible for training university teachers, especially novice teachers. In 2012, as much as 70 percent of state universities in Japan provided such training, emphasizing workplace orientation, trends in higher education, and seminars in learning processes. Other institutions provided courses in project-based teaching and activity methods. Faculties started to introduce a teaching portfolio as a tool for reflective training for academic staff and/or as a record of teaching performance. Other components included a record of research achievements (Kato, 2013).

As demonstrated by these examples, a PhD graduate who goes to work at a university benefits from support and assistance, to help them handle new tasks. 
The novice in academia becomes both

- a full-time teacher, expected to conduct seminars and review sessions, and give lectures;

- a researcher; expected to conduct independent research projects or participate in a group research project.

In addition to these two roles, the university teacher is a

- colleague, sharing in the worries, responsibilities and delights of the workplace;

- supervisor, responsible for advising bachelor's and master's theses;

- presenter, expected to publicly present the accomplishments of the department, the team, or their own;

- methodology teacher in the activities of students at preschools, primary or secondary schools.

It is difficult for a newcomer to academia to cope with all these roles, as they are heterogeneous, and each is demanding, albeit to different degrees. By adopting these roles, the novice teacher exceeds the narrow framework of workplace adaptation. Moreover, other processes must also be adapted to, including social and cultural aspects of the university.

\section{2}

\section{Social Identification}

As explained, simultaneously with embarking on a job at a university, a PhD graduate enters workplace relations while at the same time adapting to new social relations. J. Weidman (2006) describes workplace relations an essential part of social situations at the university. Each individual belongs to several social groups. Membership in a group substantially affects an individual's self-perception, which is affected by personal constructs which, in turn, shape an individual's self-concept. In an occupational group, an individual compares himself/herself with other individuals, by which the self-concept is moulded and changed.

Adaptation, then, is a process of an individual's adjustment to the environment, a situation or a group, and is closely connected with the individual's identification with a workplace. The individual identifies with social groups to which they belong, and this identification determines the way of interaction with others. This idea was developed by H. Tajfel (1982), who claims that the process of social identification is essential for understanding interpersonal interactions. Tajfel is convinced that 
human reasoning is based on the process of perception of other people and that it influences other processes, especially the formation of social norms as well as stereotypes and prejudices.

Norms, rules and goals of the group, which is joined by a new employee, are important for occupational processes. These occupational components influence the way a new university teacher will accept their position at the university.

Those study participants who started to work at the department at which they had been doctoral students were supposed to have experienced an easier social identification process, but this was not always the case. Both groups of participants faced surprises after joining the department. In addition to the roles of teacher and researcher, they became colleagues, advisors, and administrators. These were new social roles to which they had to adapt.

In academia there are many things which surprised me. People work in a stressful tempo, they do a lot of stuff, so sometimes I have difficulty in concentrating on things I would really like to do. It is not only teaching or doing research. (F4)

I do a lot of paperwork and I do not like it, and I have no time to do things I would like to do. (F1)

The study participants described unexpected responsibilities assigned to them after becoming university teachers. Suddenly, they found out that organisational tasks also belong to their duties and that they are supposed to manage them successfully.

They also became supervisors of bachelor's and master's theses. After they answered the students' questions, they began to doubt whether their advice was adequate. This led to an emphasis on self-education.

One has to think thoroughly when supervising a thesis. Only now I realised how important it is to do independent research. Then I can assist the students better. (F5)

Supervising a bachelor's thesis is sometimes a waste of time. I cannot judge how the student will accept what I am telling him. (F2)

I changed my view of supervising. I know that it is not that easy. Occasionally, I think intensely about what in fact I told the student and whether it was correct. I lack the possibility of being advised by someone. I am aware I have to know it myself. Therefore, I study diligently, I know it is a must. (F1) 
In the case I am unable to solve a problem myself, I ask someone for advice. I am happy there are people whom I can ask. (F3)

The last quotation shows that the novice teacher was seeking assistance and advice. She learned, by receiving explanations and advice, how to cope with tasks, what to do first and what to postpone. She also learned by observing the work of colleagues as well as by listening to advice on how to perform the tasks. In this social identification of the novice teacher, important roles were played by peers of a similar age with whom she discussed a full range of topics, including non-occupational matters.

It works if I sit down with my friends and discuss everything. (F1)

I do not consider myself a researcher, an inventor. But I enjoy projects with people who cooperate well. (F2)

A peer group is an important source of information about one's self. It is a group of people that the individual considers similar. Scholarly literature describes the system of peer work in accomplishing projects based on mutual help. People need support from others with the same status in doing projects because they are afraid of having discussions with "big personalities". They are sometimes distressed and unable to formulate their thoughts clearly. This can be rectified if the individuals communicate with colleagues of a similar age and status. Then they alleviate some worries and are able to engage in an effective dialogue on scientific and professional topics.

A similar-age peer group appeared to be important for the study participants after the completion of a PhD. However, the support of a peer group soon proved insufficient, because workplaces involve a range of situations as well as a range of generations.

I see how it enriches me when someone older than me expresses an opinion. He/she has more experience and sees things from completely different perspectives than we, young people. Sometimes it appeared that this solution was better, sometimes it was worse, but I do not know how I would had solved it by myself. (M1)

Discussion is cooperation. A solo player cannot do much. To tell the truth, it is a great advantage to cooperate with various professionals because it improves the person. (M2) 
As demonstrated, the effect of a same generation peer group does not explain every aspect of social interaction. The goals of people of the same generation obviously can vary, but they can merge into one workplace vision. Then the behaviour of an individual is attuned with the so-called reference group, i.e., a group of people whose opinions are considered right or acceptable in a community. Therefore, they serve as a model of behaviour. If this is not the case within a workplace, then new employees have problems, or their occupational development is retarded.

The study participants considered their relationships with other teachers and colleagues at the university to be important, as they not only served as professional support but were also sources of collegiality, which was needed because the new teachers were passing through the process of identification with a range of roles. It helped them concentrate on their work and motivated them. Those who are unable to begin such friendships face a lack of social support and social isolation.

Social isolation was described by Ali and Kohun (2006) and Baker and Pifer (2011). They pointed out that the lack of communication within a group can result in fear. The study participants appreciated the avoidance of social isolation.

If young people would not have helped me, I would have hardly managed all those things. (M3)

Frequently, social isolation is a reason for quitting a job. This, however, was not the case among the study participants. Most of them had had unsatisfying experiences at other workplaces, so they stayed.

Experiences at other workplaces made the participants aware of the importance of effective organizational management, which in their minds directly influences the employee's social identification with the workplace. Such experiences cause $\mathrm{PhD}$ graduates to value the opportunity they have received, but they were also more demanding of their surroundings and workplace conditions. They had a clear vision of the workplace management, and they knew what they wanted to avoid.

For me, the social setting I work in is of utmost importance. At my previous job, I had problems with it. I was disappointed with the quality of relationships, which were determined by the position of the boss. It is bad if personal matters intervene in important decisions. Then I said, I am quitting here. Therefore, I appreciate the setting which I have now. I have a free hand and freedom that I need in my life. We all live with the slogan, achieve first and you will be provided conditions for it afterwards. Most of the colleagues are in harmony with this slogan, so I quickly integrated with them. (M1) 
An interesting feature of this study participant's quotes is that he was consciously finding a milieu in which females prevailed. In the Czech Republic, teaching staffs are famous for being majority female. A teaching staff is a group which closely cooperates; staff members talk, exchange emotions, and show respect to each other, which supports mutual understanding. However, if such staff interaction is too frequent, it may violate the staff members' privacy. This is especially the case for males, who may experience inner tension and conflict in a female-dominated workplace.

In sum, the participants experienced the following socialisation processes in the framework of socialisation identification:

- solving day-to-day workplace issues,

- transfer of social experiences,

- interaction with colleagues.

The adaptation of the study participants to the university setting was strongly affected by social identification. A description of the concept of workplace adaptation will come in the next chapter.

\section{3}

\section{Adaptation to the University Culture}

As documented by the participants' accounts in previous chapters, occupational adaptation and social identification at the workplace are closely connected with the university culture.

The university culture, i.e., its traditions, symbols, and values, is vital to academic wellbeing because it provides stability and continuity. An institution's culture includes a complex structure of relationships, phenomena and everyday events, which gradually evolve and change. The university culture is demonstrated in its daily way of life, and it clearly distinguishes those who belong to it and those who do not. Experiencing a culture daily means sharing its ingredients and having a sense of belonging to the cultural community.

According to anthropologist Leslie White (1949), a culture is a system of symbols. Symbols are signs that are carriers of meanings in a given community. Symbols constitute an image of the institution, though culture has many other elements. For instance, Folch and Ion (2009, p. 146) delineate the university culture as a sum of convictions, values, behaviour, norms and symbols related to the following 
components: management, finances, research, instructional methods, teachers' profiles, evaluation, IT and the territorial growth of a university.

Prior to taking a job at a university, the study participants had a primary conceptualisation of the institution. For them, a university was an institution symbolized by the following:

- intelligence - "it is a place for intelligence" (F7),

- silence - "it is a space where nobody is shouting, where pupils do not rush along corridors" (F1),

- possession of time - "it is a place where I am the owner of my time" (F6),

- collegiality - "it is a place where I have colleagues and collaborators with whom I can discuss matters" (M1),

- career growth - "It is a place where I can grow professionally" (M2).

Each of these quotes indicates an element of culture that the participants believed in when they were considering joining a university. The symbol intelligence represents a belief that a university is a place where there are people whose life goals are the support of education and the creation of new values. The symbol silence signifies a desire for calmness for work, absent of shouting children. The symbol possession of time signifies a belief that time is an asset that can be managed, e.g., one can keep writing as long as desired. The symbol collegiality signifies that a university is a place of mutual understanding and cooperation. The symbol career growth signifies a belief that a university is a place where the behaviour and actions of people are aimed at professional development and work satisfaction. It is a place where the material and financial conditions are good (though not superior), allowing freedom of spirit and cooperation in creating new values.

Traditions and history also buttress the university culture. The study participants were employed at universities with the following traditions:

1. Universities that have relevant historical traditions, sometimes referred to as "stone-built universities" (M1, M2, M3, F4, F5).

2. Universities that have little-to-no historical traditions, sometimes called regional or "redbrick" universities (F1, F2, F3, F6, F7).

One important conclusion can be derived from the participants' accounts. If the participants graduated from a full-time study programme at a stone-built university, then they received a job at this university immediately upon completion of their doctorate. Typically, they were offered a job while still studying, which meant that their adaptation to the university milieu was quicker than that of $\mathrm{PhD}$ graduates who took jobs after the completion of their studies. They knew the norms and rules 
of a university, so they transferred from full-time to part-time study. The cost of this job was the prolongation of their studies. Their occupational adaptation and social identification were quick, and this influenced the course of their doctoral studies.

A half of a year into my doctoral studies, I nterviewed for a job at the department. I became a university teacher. Therefore, I switched to part-time study. Consequently, I became a member of the department from the very beginning of my doctoral studies and I had responsibilities as others had. I had a lot of tasks, and they started to accumulate. I was responsible for outreach courses, which I enjoyed, and I also did things like ERASMUS visit coordination, timetable management and the like. In addition, I had to work on my PhD. This was very demanding, it attacked my brain. One had to concentrate to manage the role of a teacher, then the role of an administrator. Only then did I have time for my PhD. (M1)

My studies lasted seven years. But during it I learned to think more thoroughly, I changed my original doctoral research project. Incidentally, I came across people who inspired me. (M2)

Those study participants who started their teaching careers at a regional or "redbrick" university first completed their PhDs and then went for a job interview, which they won. Frequently, these participants studied part-time.

I was waiting for an opportunity to apply for a job at a university. (F2)

I wanted to quit teaching at the [primary or secondary] school, so a PhD was an entry ticket to the university. (F2)

The job they received after their PhD was the first occupation in their career. In academia, they came across many factors they had to take into consideration, which was dealt with in greater detail in section 4.1.

Their conceptualisation of a university deviated from reality because they were unable to get a real picture of it (of its culture) in the course of their doctoral studies. The part-time study distorted the reality of a university.

Such findings are similar to those of Folch and Ion (2009) in their study undertaken in Catalonia. They describe two levels of the culture of a university. The first level concerns the functioning of a university as a whole. The structure of a university is determined by historical and regional traditions. In turn, these traditions are affected by political and institutional factors. The second level of the university 
culture is the creation of its values and supporting its role as a research institution. However, research is separate from instruction. A researcher and a teacher do not constitute an integrated whole. Similar ideas could be identified in the accounts of this study's participants.

The participants explained that teaching and organizational tasks dominated their initial years at the university. Researching was suppressed, while teaching was given preference. This picture was identical both in participants in stone-built and red brick universities.

On the completion of my master's I started the doctoral programme chiefly because there was no one to teach sociological courses. As a full-time student, I could not teach 10 lessons per week so I transferred to part-time study. All responsibilities began to accumulate: workplace tasks, accreditation documents, teaching and the like. It helped me to mature, but there was no time for doing research. It did not change after my completion of the doctoral programme. I do not teach less, and organisational tasks have not decreased. Although my research has been postponed, thanks to more favourable circumstances I would actually have time for it. (M2)

A university culture is also formed via teamwork. Collegiality can be deciphered in official university documents, but it also appears in a department's climate. The participants reported that the need for teamwork and the search for human interaction were important components of their workplace identification.

Sorry to say, if the climate is inappropriate, the work performance decreases. (M3)

Workplace climate is created by a pressure-free environment. (M1)

Team work helps me, so I often sit with colleagues at the office and we think, speculate, discuss things, and write... For me it is vital that next to me there is a friendly person. (F1)

Teamwork strongly supports the university culture. At those universities where teamwork is well established, the employees take it for granted and, in fact, they do not scrutinize it. A high level of identification with an institution can be conceived as a result of a melting pot of values, traditions and practices.

The work achievements of employees are determined by understanding the colleagues and their work cooperation. This was confirmed by Simplicio (2012), who claims that it is appropriate if young teachers learn to communicate effectively with older colleagues who already possess experiences and hold positions. They must 
also learn to effectively interact with colleagues to ensure that the mission of the institution is fulfilled and that students' needs are properly met. Simplicio refers to experienced academicians as "guardians of the culture" who work to maintain it and its delicate balance. "They are the keepers of the traditions and protectors of the history and culture of the institution. These individuals include veteran faculty members, entrenched staff members, and others with longevity and seniority. They stand watch over the status quo, they begrudgingly allow only the most necessary of changes, and they usher in newcomers and indoctrinate them into the field." (2012, p. 237)

In order to be successful within a university, a $\mathrm{PhD}$ graduate must learn to efficiently work with individuals, whose standing often gives them instant credibility within the professional community. If a university lacks these individuals, young people cannot observe important social models that help them to learn the academic culture.

Social isolation is the reverse of culture. Isolation can be perceived from two different perspectives, as a positive or as a negative characteristic. The study participants reported that their participation at conferences organized in the Czech Republic was rated low by the Czech Ministry of Education, therefore they avoided them. By this they isolated themselves from the professional community. ${ }^{3}$

Currently they make us isolated individuals. Unfortunately, the virtual environment has begun to be used also in academia. (M3)

Therefore, the participants much appreciated any chance of interaction with members of the professional community at conferences - if such chances existed. They considered such interactions important for their personal growth. They felt that written communication cannot substitute for face-to-face contact.

I wish there was a duty to participate at conferences. I am very grateful I have had such opportunity because it forced me to cultivate both my oral and written communication. I was learning how to cope with stress. (F6)

The opposite pole of conceiving social isolation is appreciating it. Solitude is needed if an individual works on studies and articles. The participants looked for undisturbed opportunities to work. In this respect, social isolation is a favourable matter.

3 Participation at Czech conferences brings few credit points, thus little money to a university, in contrast to international conferences. 
When I am writing a text I want to be on my own, and I seek solitude. Otherwise, I will fail. Right now, I received a review of my manuscript and I have to revise it. I am working on it vigorously. But occasionally I feel that events bother me, they interfere with my privacy. On the other hand, I cannot avoid it. (F1)

Folch and Ion (2009) conceive isolation as a kind of manifestation of freedom. Solitude is a precondition of teachers' activities. It is a necessary element for concentration on work tasks.

When I came to the university I loved to teach. But now it has changed a little. I need peace for writing. I am scared when students come and go, and this bothers me. I wish I had more freedom for quiet writing. (F2)

Social isolation, then, can be both a prison and a place of asylum. Sometimes teachers separate themselves from students and immerse themselves in their thoughts. Others literally fight for contact with colleagues and for cooperation in order to be productive. 


\section{CAREER PLANS OF PhD GRADUATES}

In the course of their PhD studies, the participants viewed the university environment through a student perspective. In addition to attending lectures and seminars, they visited offices of supervisors, teachers and university administrators. Their acquaintance with the university environment affected their occupational and academic career and influenced their personal constructs.

Workplace experiences are closely associated with workplace adaptation, in this case with adaptation to the university. Adaptation is supported by one's representation of the reality, i.e., by the way in which shared beliefs of a group of people develop and are transferred to others (Hayes, 1998). In this case, $\mathrm{PhD}$ graduates accepted social representations mediated by university employees. Social representation is traditional folk wisdom spread among institutional workers. Occupational motivation plays a vital role in the manner of acceptance of social representations.

In the previous chapter, I divided the study participants into two groups according to their method of entry into occupational careers at the university. However, I provided only a partial description of their occupational career visions. As this vision appeared to be important in the accounts of the participants, it will be the target of investigation described in this chapter. 


\section{1 \\ The Goal - Associate Professorship}

None of the participants doubted their decision to take a university job. They all found this workplace enticing and felt they belonged in it. The subsequent stages of their professional careers were subordinated to the goal of having a job at a university, or rather, to sustaining the job there. Thus, the participants realized that their professional life did not culminate in earning a PhD degree. On the contrary, they learned that this degree created an opportunity to achieve the next goal obtaining an associate professorship.

If I sum it up, I would like to be an associate professor, and I hope I shall be one day. I want to extend my contract with the university, and I know how important this degree is. It increases the chance that they will let me work here. (F2)

Because I want to remain at the university, there is no other option than to struggle for an professorship. (F1)

Universities push teachers to produce "normed" achievements and to follow prescribed career routes. Publications and higher degrees increase the credibility of a university. Thus, teachers are directed by departments to set out on the track of earning an associate professorship within five to ten years after earning a PhD.

At our faculty, career growth is closely followed. Simply, we receive deadlines from administrators for reaching the next career stage. I am aware that I must be an associate professor. However, one has to have time to mature. Unfortunately, it seems that a university is a kind of a factory for producing associate professors, and I do not think some individuals are mature enough for it. (M3)

University pressures, as described by the participant, are understandable. A university needs "recognized publications" by employees in order to qualify for programme accreditation. Publications and accredited programmes, in turn, are criteria for the government subsidisation of a university, including the subsidy for number of students. However, the professional and personal maturation of teachers varies. The number of students who earn a PhD at the age of 25-30 increases every year. In the past, it was usual that a university teacher first earned a PaedDr degree (lower level doctorate in pedagogy) and only then enrolled in a $\mathrm{PhD}$ programme. In principle, a $\mathrm{PhD}$ was earned ten years after receiving a master's degree, and a $\mathrm{PhD}$ graduate was 30-40 years old. Nowadays, the age level is lower. An individual 
enrolled in PhD studies can earn their degree at the tender age of 25. From this, it follows that a university teacher can be an associate professor at the age of 35 . According to formal criteria, such quick advancement is possible.

Concerning the age of earning a PhD, the study participants can be divided into two groups:

- Those who earned a PhD before age 30.

- Those who earned a PhD at age 35 or later.

The first group is well represented by these quotes:

I have a lot of publications; however, I am unable to find a topic suitable for earning an associate professorship. A principal topic is required for it. But nobody will tell you which topic is principal. Therefore, many of us inspected the topics that had been defended. And the task is to detect why a topic was or was not successful. (M3)

When I was a student, I thought that if somebody was an associate professor or a full professor his books would stuff the shelves in a library. A professor is a man of reputation. Then I learned that this was not always true. One can earn these degrees quicker and in a smooth manner. (F6)

Participants of the second group are represented by the following quotes:

I am thinking of associate professorship but, to tell the truth, I hate if a colleague boasts of this degree and I know how easily he earned it... and then I said to myself if an idiot like he did it why should I not do it myself. On the other hand, if such idiots pile up, then one can ask if having this degree would not assign you to a bad society... so everything needs time. (M2)

In the beginning, when I got the job at the university, I thought this was very easy. It simply goes by itself, quickly. These ideas were naïve. I did not know precisely how to earn an associate professorship. That is why I thought it was easy. I know now that it will not go rapidly, but the direction is clear. (F1)

I do not hurry to earn an associate professorship. I desire to be considered a reputable professional. One needs time to mature. (M1)

In the accounts of participants who belong to the first group, it appears that they found a research topic by searching the already-defended dissertations. This, 
however, is an obscure practice of someone who wishes solely to earn a higher degree. A candidate should be a specialist in a particular field and well known in the professional community for a contribution to the development of this field.

In the first group, academic career acceleration seemingly rests on finding ways to ease the promotion process, or putting it bluntly, to play the system. In addition, the first group's conceptualisation of an associate professor's responsibilities appears inaccurate, as witnessed by the following quote:

When I become an associate professor, I will not be burdened by trifling matters, I will have more time to conduct research, I will have more influence, and I will meet relevant people. I will have a higher position than I have now. Associate professorship will make it possible to reach things that are currently unreachable. (F1)

In the second group, participants were aware that personal maturity is a necessary characteristic of associate professorship. The two groups differed in considerations of what an associate professor should do. The participants conceptualised associate professorship chiefly in relation to research, advising and assisting others.

An individual becomes an associate professor if he/she can advise others, if the individual subordinates their own benefits to the benefits of others, if he/she has a strong will to develop professionalism and if others consider him/her an expert in a field. (M1)

The professional routes of the two groups are depicted in Table 1:

Table 1 Professional routes of the two groups

First group = academic route No. 1

Rapid pace of PhD studies; usual duration of 3 years.

Age of completion, 25-27

Naïve conceptualisation of PhD

studies; strong motivation for earning an associate professorship.

Effort to ease the route to associate professorship.

\section{Second group = academic route No. 2}

Slower pace of $\mathrm{PhD}$ studies, usual duration of 5-7 years.

Age of completion, 30+

Strong motivation for research projects.

Higher self-demands. 
A distinct characteristic of the first group is conformity. The individual has quickly adapted to the options available for career advancement. Individuals in the second group are less conforming; they have high self-esteem and high confidence in their abilities. They aim to build excellent reputations in their fields and try not to ease the route to an assistant professorship.

It is impossible to identify causality between the level of conformity of a student and the quality of the doctoral studies. This was neither the aim of the chapter, nor can it be supported by the research data. However, the possible existence of such a causality might be worth future investigation.

\section{2}

\section{A teacher and a Researcher}

In addition to describing their career advancement, the participants explained visions of their professional growth, or rather of work improvement at a university. In their accounts, they described themselves as teachers and as researchers. In previous chapters, I have indicated that it is difficult to find a balance between the role of a teacher and that of a researcher at a university. The participants' views on their university positions were influenced by their university employment contracts and by several years of experience, both of which helped determine their next professional steps.

The participants identified easily with the role of a university teacher because they previously taught at primary or secondary schools, making the role of an educator familiar to them. They knew instructional principles and didactical rules. This explains why they enrolled in pedagogy rather than in other disciplines. But the participants admitted they needed improvement in teaching skills. They teach adults, which is much different from teaching children. The participants stressed that instructional practices and pedagogical philosophies keep evolving, which challenges them.

To grow professionally, the participants

a) studied professional literature.

I moved further and further to new teaching methods, I searched in books, method manuals, or foreign publications. I desired to give students a lot of knowledge. (F7) 
b) attended courses and workshops.

I used to travel to attend workshops in Prague, then in Brno. They were excellent, I learned a lot and I used it in the classroom. (F6)

c) had discussions with colleagues.

It is important to meet people, discuss my opinions with a colleague. This increases the chances of enriching students. (M2)

All of the study participants expressed a desire to assist students in their learning, which agrees with the findings of G. S. Åkerlind in her research conducted at an Australian university (2007). University teachers focused on building a better knowledge of their content areas, in order to become more familiar with what to teach. They also continually increased their understanding of what works and does not work for students, in order to become more effective in facilitating student learning.

The instructional content and structure are in the teacher's hands, but they are in part shaped by accreditation documents, which, however, provide only an interpretation framework for the curriculum. The participants expressed the need for practical teaching skills and the development of a repertoire of instructional strategies. They also found it important to detect which strategies work best in providing content to students. They also considered how to adopt the teaching content to a particular class, how to present a topic to students as efficiently as possible, how to motivate them for learning, how to assign tasks and how to assess them. These activities, of course, are only a part of a university teacher's work.

University teaching is an occupational position within which educational, scientific, research and developmental activities are required, the results of which are then passed along to students. The full list of these activities is long, and the study participants have not yet met many of them. However, during their academic career, they will come across new tasks, which will bring new challenges.

According to the study participants, a university teacher accomplishes these tasks:

- delivers lectures, leads seminars and organizes workshops,

- provides consultations,

- supervises theses and dissertations,

- develops organisational plans, 
- proposes projects,

- publishes textbooks and other learning materials,

- publishes studies,

- cooperates with partners in the field,

- searches for and analyses new knowledge in the field,

- performs administrative tasks.

Of course, the participants have a simplified view of university teacher responsibilities, which reflects their narrow experience. Note, for instance, that the list does not contain academic research, which the participants were reluctant to talk about it - either theirs or their colleagues'.

Studies on becoming a professional researcher are numerous, and there is a wealth of research data on becoming a teacher. Åkerlind (2008) identified four stages in the development of a researcher:

1. Becoming confident as a researcher. This stage involves acquiring the skills required to do research successfully, such as learning how best to choose a research topic, to give conference papers and write-up results, to do literature searches, etc. It might also involve clarifying a future research direction.

2. Becoming recognised as a researcher. In contrast to the previous stage, which involves the development of an internal sense of competence and success, this stage includes external recognition of one's competence and success by other academics in one's field. This is marked by becoming part of a research community, building a reputation in the community and having one's ideas adopted and used by others.

3. Becoming a more productive researcher. This stage views development as a quantitative increase in researcher productivity, that is, conducting larger research projects, teaching more $\mathrm{PhD}$ students and postdocs, receiving more funding, and more publishing. This increase can involve the simple accumulation of research activity over time and/or an increase in the rate of productivity through improved efficiency and the beneficial impact of one area of activity on another.

4. Becoming a more sophisticated researcher. This stage extends from the quantitative changes described in the previous category, to include a focus on qualitative changes as part of researcher development. These qualitative 
changes involve developing greater sophistication in thinking, becoming more theoretically aware, increasing breadth of knowledge, developing a greater depth of understanding, becoming aware of wider perspectives, being better able to resolve issues and having an enhanced capacity to do research.

The participants in this study belong to the first developmental stage, higher stages being far away from their present research competences. It should be noted, however, that Åkerlind's sample included postdocs, which were not present in my sample.

In many countries, academic support is offered to postdocs through a variety of projects. This is in contrast to the situation in the Czech Republic, in which PhD graduates are not provided specific assistance to enhance their research capacity. They are expected to be fully-developed researchers upon taking a teaching position at a university.

The participants who took academic route No. 1, defined previously, were explicit in describing their problems with starting a research project.

I failed to start my research. I wish I could be involved in a project, or propose one of my own, but I cannot decide on the topic. I feel like I am an apprentice. (F4)

The participants have not yet reached the stage of a productive researcher. For them, independent research projects were faraway targets. But this might change in the future. Rather than concentrating their efforts on growing academically, they criticise the career rules and wait for external support.

I want someone to supervise me, but they expect publications from me in order to gain points for some evaluation. I wish someone will come to me and offer participation in a career someday. (F5)

The participants that follow academic route No. 2, who had a slower career pace, appeared to make an effort to build a positive reputation within the academic community.

I am happy if I do meaningful things - if the topic is interesting and I collaborate with reasonable people. I am happy if I can present my findings and they are accepted by the community and cited. (M2)

Quite recently I published a book, which made me very happy. I have received favourable references, which pleases me. This is how I build respect within the academic community. (F2) 
As noted, some of the participants feel a need for acceptance within the academic community. It is of value for them because it is in harmony with their view of their career growth. They also are aware of the importance of conducting research projects.

I like doing projects, but in the Czech Republic large projects, such as those funded by the Czech Science Foundation (GA ČR), but they are accessible only to the chosen. I do not know how the selection is being made, but in the list of approved projects one can repeatedly see the same names. (M2)

I have no chance to analyse and evaluate the objectivity of the system of approval of the Czech Science Foundation proposals. PhD graduates generally have an opportunity to apply for the so-called junior projects. Nevertheless, the criteria are strict, and only a small percentage of $\mathrm{PhD}$ graduates can meet them. One of the criteria is at least six months studying and teaching abroad.

One of the participants succeeded in gaining a Czech Science Foundation grant, and he finds it an excellent research experience.

I managed to receive a Czech Science Foundation grant. It was demanding but I am fond of research methodology. I had some knowledge of statistics, I read Kerlinger and such stuff, but now I am excited about the qualitative route. Suddenly, I found out that figures must be verbally interpreted to express meaning, and if I want to get underneath, there is no other direction. (M1)

A young researcher should start their career with small projects, and only then proceed to larger ones. The Ministry of Education of the Czech Republic offers grants to support so-called specific university research (IGA). Every university has its own grant rules. Many universities support specific university research projects, which are targeted to doctoral students and postdocs. Some faculties offer grants for university teachers in collaboration with graduate student programmes. With this, a teacher takes up a more demanding role, as he/she must be able to propose a team project in order to succeed.

One of the participants has had experience with IGA projects.

Now we have an IGA and we enjoy it. We are four women in the team. The collaboration is interesting and we learn a lot. We discuss matters, and discussion means collaboration. We find solutions about our topic. (F2) 
A beginning university teacher needs time to grow to be a researcher. Experience in research is needed. The faculties that hire young PhD graduates should create the right research conditions and emphasize the important role of research in academia. It should be the strategy of a university to support PhD graduates not only to become teachers but also researchers. ${ }^{4}$

4 This is in contrast with most of the West European and North American universities, which that are either teaching universities or research universities. 


\section{CAREERS OF YOUNG UNIVERSITY TEACHERS IN THE CZECH REPUBLIC}

\section{1}

\section{Career Decisions Made by University Teachers}

Previous chapters described the professional and academic careers of the study participants from the completion of their master's studies to their work at a university. This chapter synthesizes these findings. The data and categories were merged to form concepts and relationships that constitute a theoretical model of occupational and academic careers, including career determinants.

The study participants had personal values that influenced their beliefs about attaining university employment. They desired to work in academia and therefore concentrated their efforts towards reaching this goal. On the route to the position of a university teacher, each participant had at their disposal a set of career options and a repertoire of possibilities that could be used to achieve personal satisfaction. Their decisions were influenced by a range of career possibilities and opportunities. These personal decisions and their key determinants were integrated into a model that is depicted in Fig. 3 (next page).

According to Kelly and Hayes, key personal potentials are the abilities, values, and beliefs of an individual. They strongly affected the participants' behaviours and activities aimed at obtaining a job contract at a university. Personal potentials strongly interact with the family environment of an individual and with an individual's self-concept. A personal community consists of close relatives and friends. In general, a personal community motivates and stimulates an individual to utilize career possibilities and opportunities. To develop a sound self-concept and attain occupational success, a university teacher generally needs a satisfactory 


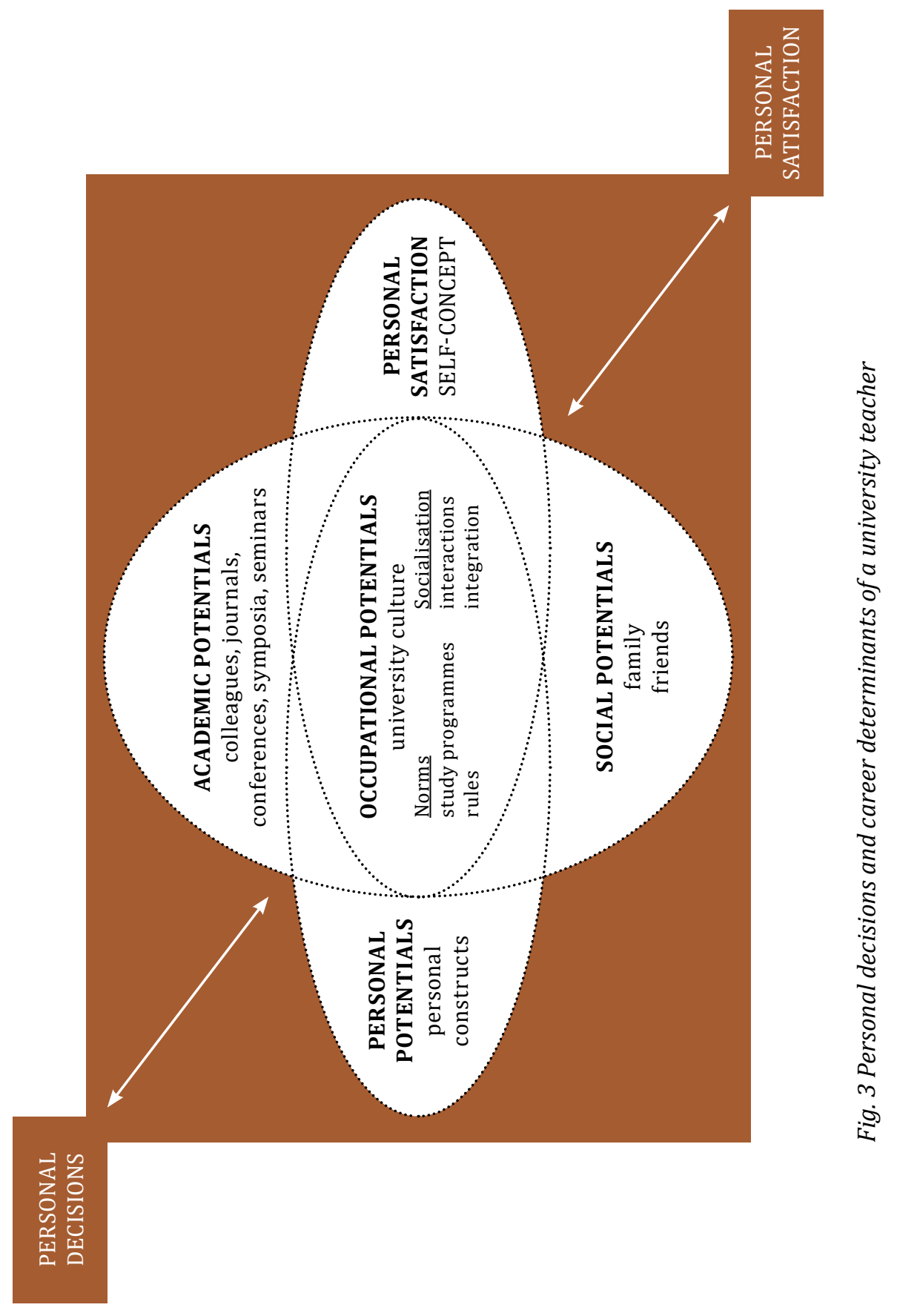


family milieu, and sympathy as well as a support from relatives and friends. Such a support was reported by study participants to be a strong emotional stimulus, especially if accompanied by financial and material aids.

A teacher's job at a university requires much understanding and extensive support from the immediate environment. The participants reported that family and friends had affirmed for them that they belong at a university and deserve a respected position in the academic community.

Occupational potentials are conditions of the university milieu. On the one hand, a university introduces norms and rules that regulate the employees' work. On the other hand, a university enables interactions among colleagues and students who constitute the academic community. A university needs to develop a culture that generates a teacher's personal satisfaction and motivation for high achievements.

The core component of academic potentials is an academic community, which is constituted by colleagues at a home university. A university teacher is gradually integrated also into a broader academic community, represented by partners from other universities. A teacher's scholarly reputation is gained by publishing quality research papers and monographs but also in face-to-face contacts in seminars, conferences and symposia. Experiences and knowledge exchange, both in domestic and international scientific events, shape a teacher's academic self-concept.

Over time, career possibilities and opportunities change. In order to make efficient career decisions, a university teacher assesses them. The interaction of decisions with career possibilities and opportunities has a significant influence upon the sequence of a teacher's career stages.

\section{2 \\ Trajectories in the Occupational and Professional Careers of University Teachers}

A professional career is defined as a sequence of linear stages in the life of a university teacher. According to Savickas $(2002,151)$, a career sequence can be objectively observed by scholars or subjectively disclosed by an individual. The two perspectives yield a different picture of a professional career. The subjective perspective shows how an individual conceptualizes his/her life and interprets experiences. This aspect was used in the analysis and understanding of empirical data gathered from the study participants. This chapter describes relationships 
between the occupational and professional careers of the study participants as embodied in their career trajectories.

The study participants had clear visions of their professional careers, their key aim being to succeed in an occupational career. They desired to secure a job at a university. The data do not reveal what influenced their views during undergraduate and graduate studies; it only can be assumed that their personal constructs, which were academically-oriented, were formed as early as during their master's studies.

The participants viewed a doctoral degree as an entry ticket to university employment. This was one of the key motives for their enrolment in a doctoral programme. Their personal constructs were supported by family, friends and the close environment, as well as by their thesis supervisors. The supervisors considered some of them (M1, M3, F3) potential doctoral students as early as in their master's studies, so they offered to supervise their doctoral dissertations. The data identifies four trajectories that the study participants followed to attain a university job.

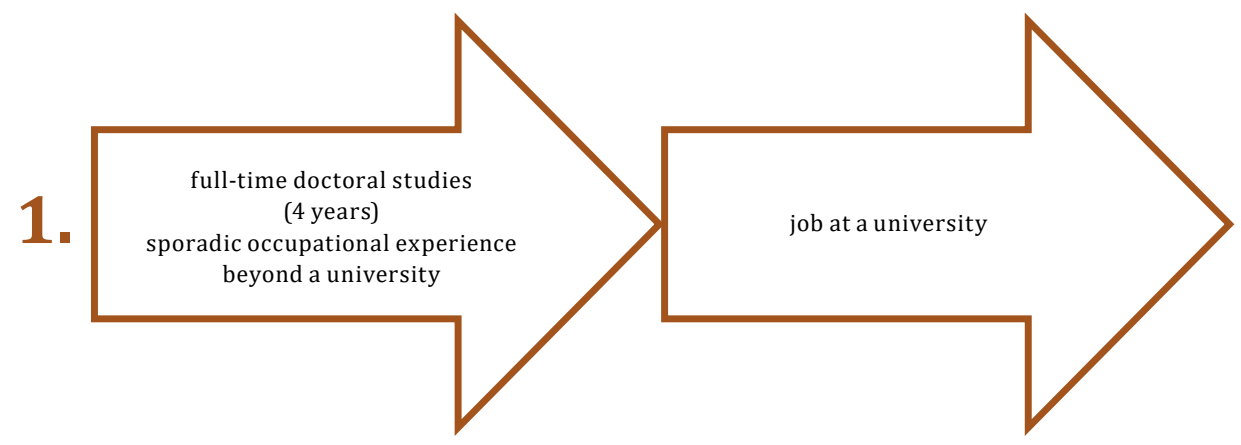

Fig. 4 Career trajectory one

In the first trajectory, the doctoral studies were completed in four years and the PhD graduate was 25-26 years old. The individual had sporadic and irregular jobs during the studies, which ensured financial survival but did not satisfy the individual. After completion of the doctoral studies, a university job was obtained. This trajectory represents a direct route from studies to university employment. However, in this career stage, a professional career is not yet firmly established. As explained in Chapter 1, the professional career is is a broader concept than the occupational career, with the former exceeding the latter. The professional career is not connected with a single institution but with all institutions (in one professional domain) for which the individual worked. A professional career is 
linked with the profiling of a university teacher in the professional community, and not with a single occupation.

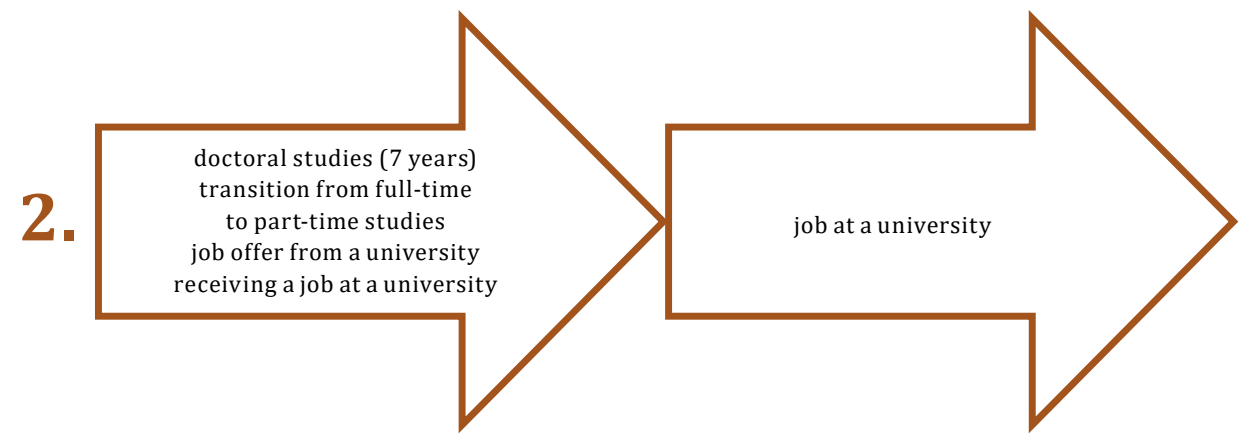

Fig. 5 Career trajectory two

In the second trajectory, the study participants had a job as early as during their doctoral studies, and a PhD helped them to secure it. However, by transferring to the part-time programme, they extended their studies up to seven years. They earned a PhD at the age of 30-31. Being university teachers, they were impelled to publish, make contacts in the academic community and earn academic experience, thus, their professional career started before earning a PhD. When they completed the studies, they had already completed the initial stage of a professional career.

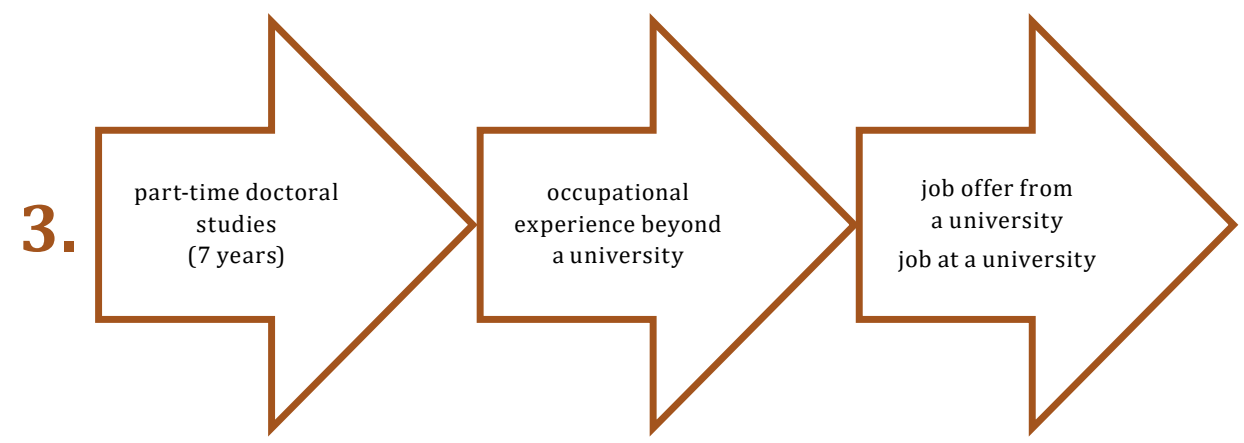

Fig. 6 Career trajectory three

Representatives of the third trajectory started their occupational careers in other employment fields but, after some time, they found their way to becoming university teachers. Thus, they already had occupational experiences, though unsatisfactory, which made them consider career opportunities at a university. 


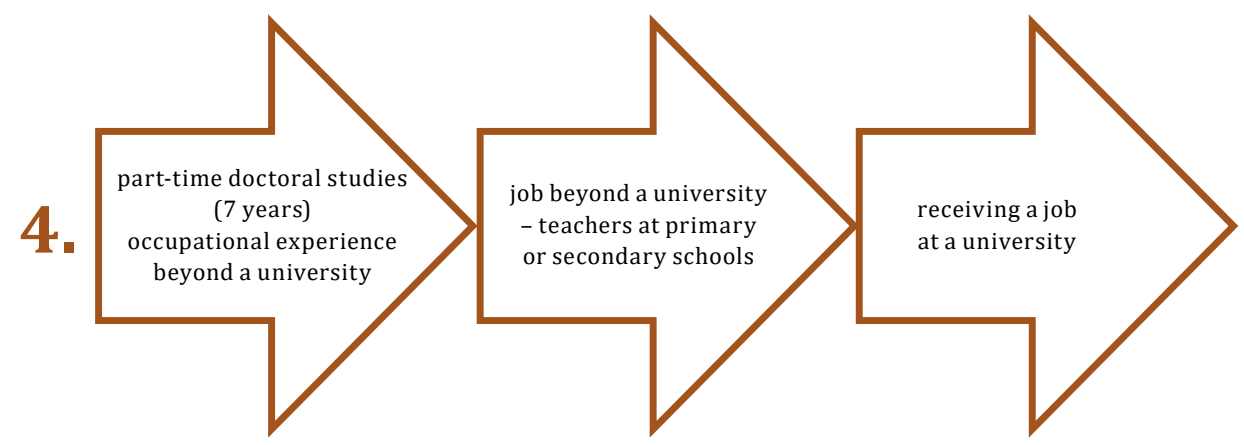

Fig. 7 Career trajectory four

The fourth trajectory was the longest one. The participants studied for seven years in a part-time doctoral programme, which they completed at the age of 30-31. Before enrolment, they had already started their occupational career as teachers at primary or secondary schools. This was the beginning of their professional career. After several years of teaching experience, they found career opportunities at a university.

Doctoral studies, university rules and possibilities offered by a university milieu, the relationship with a supervisor, early publishing experience, contacts with teachers at other departments - all this shaped the personal constructs, values and personal decisions of the study participants and helped form their professional self-concepts. Family and friends had an important influence on their professional maturation. They reinforced the already-developed professional self-concept, and their professional careers began to obtain clear contours.

How the next stages of the professional life of the study participants will develop is difficult to anticipate. Time will show in which directions and places their professional careers will move, though one fact is certain: they all declared the career aim to retain a long-term contract at a university. This aim was present in a number of statements about their future professional life, for instance, in their desire to earn an associate professor's degree, a precondition for getting a longterm job contract at a university.

The data indicate that $\mathrm{PhD}$ graduates set out towards the occupation career of a university teacher thoughtfully and consciously. They were aware of their occupational aims, and they had their personal constructs, which supported their decisions about a professional career. They have developed a life philosophy of struggling 
eagerly for career success, and they desired to be professionally distinguished from primary and secondary school teachers. Their occupational self-concept was gradually strengthening after obtaining an employment contract at a university.

It is not easy to predict how the professional and occupational career trajectories of the study participants will develop in the future. Each of them is heading along their own route. Decisions about professional careers will be made based on growing academic experience, family situation, changes in the personal construct and self-concept. Time will dictate whether the career decisions of the study participants will result in professional satisfaction. 



\section{CONCLUSION}

My original intention before starting the research described in this book was to analyse the development of young researchers. I wanted to concentrate on how their research competences for designing and accomplishing research projects evolved during their doctoral studies and after gaining a job as a university teacher, and how these competences were utilized in their research projects. I wanted to hear how they struggled with intricacies of working with study respondents, how they composed their research tools and how they wrestled with advanced statistical methods. I also expected that they would depict a vision of their future research, describe their research plans, and anticipate their developmental potentials in the scholarly field. Very little of this was present in their accounts.

After the interviews with the study participants started, it became clear that this would not be the key topic of the book. Rather, the interviews turned to capture what the study participants considered a major issue: the details of their occupational careers. All participants viewed the peak of their careers as university teachers, and they subordinated to it their personal and occupational lives. The interviews strongly support the finding that the main reason to enter into the doctoral programme was not to be become teachers or researchers but to get a job at a university. A PhD was an entry ticket to employment in academia.

Why was a university considered their career target? As it appeared in the study participants' accounts, the key reason was the professional status they gained by becoming university teachers, a position much valued within their social setting (family, friends, and the community). The professional status was more appreciated than the salary, which is, by the way, not high if compared to other highly-qualified employees in the Czech Republic. Furthermore, they witnessed that a university offered them intellectual liberty, spiritual freedom and opportunity 
for self-improvement. The latter was not associated with knowledge and skills to conduct research. A researcher was not described as a career target.

The study participants provided thorough reports about their doctoral studies, and their reminiscences revealed the conditions for PhD studies in pedagogy that were far from ideal. They showed problems that still persist in these doctoral studies. In particular, they stressed inefficient relationships with supervisors, large administrative tasks assigned to them by heads and senior officers, and little support for the development of teaching skills.

The study participants confessed that teaching was easier for them than doing research. In their opinion, teaching was based on reading a subject matter and then delivering it to students. This is not a sophisticated higher education practice. Nobody taught them how to develop their teaching potentials, and they probably never heard how to integrate research findings into their university courses.

The problem of developing skills of teaching must be overcome by providing the young teacher with systematic training in university instruction. In the chapter about occupational adaptation, I mentioned such a training programme in Finland. It consists of courses about elements of university teaching, learning environment, linking research and instruction, and social and cultural aspects of the university environment (Murtonen \& Lappalainen, 2013). Similar teacher adaptation programmes are provided for novice university teachers in Japan (Kato, 2013).

What my study participants lacked in their initial teaching practices was a mentor. Good universities assign a mentor to a novice university teacher, usually an experienced colleague who acts as a role model and provides systematic guidance in instructional matters. They are invaluable help for an inexperienced teacher.

Another point worth discussing is the position of postdocs. Generally speaking, a postdoctoral position is a temporary post in which a $\mathrm{PhD}$ graduate receives continuing training in research. A postdoc position is a transitional post to a permanent career in academia or another higher institution. In contrast to the sciences, Czech universities offer very few postdoc positions in pedagogy. Postdoctoral practice and training provides a young researcher with developmental opportunities. This requires that the university has specialists who concentrate on supporting professional development. Many universities in other countries nominate postdoctoral trainees and offer a special programme concentrating on those who guide the postdoc throughout their programme. A good example is the University of Alabama at Birmingham (Lorden \& Matalon, 2002, p. 49).

Czech universities would benefit from professional developmental programmes offered to $\mathrm{PhD}$ graduates in pedagogy. These programmes would not only help young professionals but would also improve the professional reputation of the university. Such programmes would include "learning to live" at a university: ethics in science, 
professional as well as civil engagement. The political and financial conditions of universities could be adjusted in order to include young teachers' mentoring as a key task.

Another thing that young teachers need is assistance in creating an overall career plan. Such a plan cannot be built by a young employee individually: rather, the university would offer to create it. Such a career plan and its application would reduce employee fluctuation. These career plans must include visits to universities abroad or study visits that would assist in the professional development of a young employee. Foreign language competence is an inevitable prerequisite of such visits. Though currently the universities in the Czech Republic do not rate presentations at international conferences high, it is not wise to exclude this option from the opportunities of communication in professional communities. A young researcher must build a reputation in the professional community. Exchanges of ideas in international forums is one of the means to support it.

The ideas presented here that aim at improvement of university practices toward helping young teachers were generated from the small sample of the study participants. They cannot serve as firm standpoints. Rather, they must be validated with a larger sample of respondents. The results of such investigations are important for future practices of universities as regards the career planning and quality professional development of young university teachers.

This book was unable to provide answers to all questions concerning careers of young teachers. Neither was it its aim. However, I believe the findings and ideas presented here will generate questions concerning the topic and may start large scale investigations thereof. Time will show to what degree the issues were resolved. 



\section{REFERENCES}

Åkerlind, G. S. (2003). Growing and developing as a university teacher - variation in meaning. Studies in Higher Education, 28(4), 375-390.

Åkerlind, G. S. (2007). Constraints on academics' potential for developing as a teacher. Studies in Higher Education, 32(1), 21-37.

Åkerlind, G. S. (2008). Growing and developing as a university researcher. Higher Education, 55(2), 241-254.

Ali, A., \& Kohun, F. (2006). Dealing with isolation feelings in IS doctoral programs. International Journal of Doctoral Studies, 1(1), 21-33.

Armstrong, M. (2002) Personální management [Personal management]. Praha: Grada.

Anderson, M. T., Ingram, J. M., Buford, B. J., Rosli, R., Bledsoe, M. L., \& Onwuegbuzie, A. J. (2012). Doctoral students' perceptions of characteristics of effective college teachers: A mixed analysis. International Journal of Doctoral Studies, 7, 279-309.

Arnold, J. (1990). From education to job markets. In S. Fisher \& C. L. Coopet (Eds.), On the Move: The Psychology of Change and Transition (pp. 207-229). Chichester: Wiley.

Arnold, J., \& Nicholson N. (1991). Construing of self and others at work in the early years of corporate careers. Journal of Organizational Behavior, 12(7), 621-639.

Austin, A. E. (2002). Preparing the next generation of faculty: Graduate school as socialization to the academic career. The Journal of Higher Education, 73(1), 94-122.

Austin, A. E., \& McDaniels, M. (2006). Preparing the professoriate of the future: Graduate student socialization for faculty roles. In J. C. Smart (Ed.), Higher Education: Handbook of Theory and Research (pp. 397-456). Dordrecht: Springer.

Backman, K., \& Kyngäs, H. A. (1999). Challenges of the grounded theory approach to a novice researcher. Nursing \& Health Sciences, 1(3), 147-153. 
Baker, V. L., \& Pifer, M. J. (2011). The role of relationships in the transition from doctoral student to independent scholar. Studies in Continuing Education, 33(1), 5-17.

Bandura, A. (1997). Self-efficacy: The Exercise of Control. New York: Freeman.

Brailsford, I. (2010). Motives and aspirations for doctoral study: Career, personal, and inter-personal factors in the decision to embark on a history PhD. International Journal of Doctoral Studies, 5(1), 15-27.

Braun, V., \& Clarke, V. (2006). Using thematic analysis in psychology. Qualitative Research in Psychology, 3(2), 77-101.

Brooks, I. (2003). Firemní kultura [Company culture]. Brno: Computer press.

Brown, C. A., \& Detoy, C. J. (1988). A comparison of the personal constructs of management in new and experienced managers. In F. Fransella \& L. Thomas (Eds.), Experimenting with Personal Construct Psychology (pp. 426-433). London: Routledge.

Bruinsma, M., \& Jansen, E. P. (2010). Is the motivation to become a teacher related to pre-service teachers' intentions to remain in the profession? European Journal of Teacher Education, 33(2), 185-200.

Davis, G. (2013). Advising and supervising doctoral students: Lessons I have learned. University of Minnesota. Retrieved from http://misrc/umn.edu/workingpapers/ fullpapers/2004/0412 052404.pdf.

Dawson, N. (2007). Post postdoc: Are new scientists prepared for the real world? BioScience, 57(1).

Eccles, J. S. (1994). Understanding women's educational and occupational choices. Psychology of Women Quarterly, 18(4), 585-609.

Elliot, R., \& Timulak, L. (2005). Descriptive and interpretive approaches to qualitative research. A handbook of research methods for clinical and health psychology. 147-159.

Flešková, M. (2007). Sociálne skupiny [Social groups]. In M. Verešová et al. (Eds.), Sociálna psychológia [Social psychology] (pp. 191-222). Nitra: Enigma.

Folch, M. T. \& Ion, G. (2009). Analysing the organizational culture of universities: Two models. Higher Education in Europe, 34(1), 143-154.

Fournier, V., \& Paine, R. (1994). Change in self construction during the transition from university to employment: A personal construct psychology approach. Journal of Occupational and Organizational Psychology, 67(4), 297-314.

Fransella, F., \& Dalton, P. (1990). Personal Construct Counselling in Action. London: Sag.

Gardner, S. K. (2007). "I heard it through the grapevine": Doctoral student socialization in chemistry and history. Higher Education, 54(5), 723-740. 
Gavora, P. (2013). Úloha školitel'a pri výchove doktoranda [Supervisor's role in supervising]. In: A. Wiegerová (Ed.), Začínající výzkumník [Beginnig researcher] (pp. 34-49). Zlín: UTB.

Goffman, E. (1959). The presentation of self in everyday life. 1959. Edinburgh: Universityof Edinburgh.

Hackett, R. D., Lapierre, L. M., \& Hausdorf, P. A. (2001). Understanding the links between work commitment constructs. Journal of Vocational Behavior, 58, 392-413.

Harkin, S. G., \& Jackson, J. M. (1985). The role of evaluation in eliminating social loafing. Personality and Social Psychology Bulletin, 11(4), 457-465.

Hayes, N. (1998). Psychological processes in organisational cultures I: Social representations and organisational semiotics. Human Systems, 9(1), 59-65.

Hayes, N. (2002). Psychologie týmové práce [Teamwork psychology]. Praha: Portál. Hebden, J. E. (1986). Adopting an organization's culture: The socialization of graduate trainees. Organizational Dynamics, 15(1), 54-72.

Heitlingerová, A., \& Trnková, Z. (1998). Životy mladých pražských žen [Lives ofyoung Prague women]. Praha: Slon.

Honess, T. M. (1989). A longitudinal study of school-leavers' employment experiences, time structuring and self-attributions as a function of local opportunity structure. British Journal of Psychology, 80(1), 45-77.

Horta, H. (2009). Holding a post-doctoral position before becoming a faculty member: does it bring benefits for the scholarly enterprise? Higher Education, 58(5), 689-721.

Hughes, E. C. (1958). Men and their Work. Glencoe, IL: Free Press.

Janesick, V. (2003). The choreography of qualitative research design: Minuets, improvisations, and crystallisation. In N. Denzin, \& Y. Lincoln (Eds.), Strategies of Qualitative Inquiry (pp. 46-79). Sage, Thousand Oaks.

Jaraim, D., \& Kahl, D.H. (2012). Navigating the doctoral experience: The role of social support in successful degree completion. International Journal of Doctoral Studies, 7, 311-329.

Jefferson, G. (2004). Glossary of transcript symbols with an introduction. Pragmatics and Beyond New Series, 125, 13-34.

Kato, K. (2013). University teacher training in Japan. Revista de Docencia Universitaria, 11(3), 53-63.

Katzenbach, J. R., \& Smith, D. K. (1993). The wisdom of teams: Creating the highperformance organisation. Boston: Harvard Business School.

Keenan, A., \& Newton, T. J. (1986). Work aspirations and experiences of young graduate engineers. Journal of Management Studies, 23(2), 224-237. 
Kelchtermans, G., \& Vandenberghe, R. (1994), Teachers' professional development: A biographical perspective. Journal of Curriculum Studies, 26(1), 45-62.

Kelly, G. A. (1970). A brief introduction to personal construct theory. In D. Bannister (Ed.), Perspectives in Personal Construct Theory, 1-29.

Kelly, G. A. (1977). The psychology of the unknown. In D. Bannister (Ed.), New Perspectives in Personal Construct Theory, 1-19.

Kern, H., Mehl, C., Nolz, H., Peter, M., \& Wintersperger, R. (2015). Přehled psychologie [Overview of psychology]. (5th ed.) Praha: Portál.

Kirkpatric Johnson, M. \& Mortimer, J. T. (2002). Career choice and development from a sociological perspective. In Brown, D. et al. Career choice and development. 4th ed. (37-81). San Francisco: John Wiley \& Sons.

Kosová, B. (2013). Vysokoškolské vzdelávanie učitel’ov na Slovensku [University education of teachers in Slovakia]. Pedagogika, 63(4), 485-500.

Latané, B., Williams, K., \& Harkins, S. (1979). Many hands make light work: The causes and consequences of social loafing. Journal of Personality and Social Psychology, $37(6), 822-832$.

Latham, G. (2011). Work Motivation: History, Theory, Research and Practice. NJ, SAGE.

Leitner, L. M. (1988). Contextual shifts in interpersonal constructions. In F. Fransella \& L. Thomas (Ed.), Experimenting with Personal Construct Psychology (pp. 308-318). London: Routledge.

Levy, Y., \& Ellis, T. J. (2011) A guide for novice researchers on experimental and quasi-experimental studies in information systems research. Interdisciplinary Journal of Information, Knowledge, and Management, 6, 151-161.

Lorden, J. F., \& Matalon, S. (2002). Easing the perils of the post-doctoral years a call for institutional attention. Change, 34(1), 44-49.

Louis, M. R. (1980). Surprise and sense making: What newcomers experience in entering unfamiliar organizational settings. Administrative Science Quarterly, 25, 221-231.

Lukášová, H. (2015). Učitelské sebepojetí a jeho zkoumání [Teachers' self-concept and its investigation]. Zlín: UTB.

Mabey, C. (1986). Graduates into industry - a survey of changing graduate attitudes. Aldershot: Gower.

Mareš, J. (2012a). Pedagogická psychologie [Educational psychology]. Praha: Portál. Mareš, J. (2013b). Neviditelná skupina aneb co s postdoktorandy? [An invisible group or what to do with postdocs?]. Pedagogická orientace, 23(1), 5-26.

Mareš, J. \& Ježek, S. (2013). Kvalita doktorského studia na UK z pohledu absolventů [The quality of doctoral programmes at Charles University - the view of PhD graduates]. Forum 3/2013 sešit 27, 25-29. 
McAlpine, L., Jazvac-Martek, M., \& Hopwood, N. (2009). Doctoral student experience in Education: Activities and difficulties influencing identity development. International Journal for Researcher Development, 1(1), 97-109.

Melin, G. (2005). The dark side of mobility: negative experiences of doing a postdoc period abroad. Research Evaluation, 14(3), 229-237.

Miles, M. B., Huberman, A. M., \& Saldaña, J. (2014). Qualitative data analysis. 3rd edition, Los Angeles: SAGE.

Milkovich, G. T., \& Boudreau, J. W. (1993). Řízení lidských zdrojů [Managing human resources]. Praha: Grada.

Miller, D. I., Eagly, H., \& Linn, M. C. (2015). Women's representation in science predicts national gender-science stereotypes: Evidence from 66 nations. Journal of Educational Psychology, 107(3), 631-644.

Murtonen, M., \& Lappalainen, M. (2013). Pedagogical education for university teachers in Finland. Revista de Docencia Universitaria, 11(3), 65-72.

Neusar, A., Charvát, M., Dolejš M., Smetáčková I., Kolařík M., Kundrát J. ... Szarzyńska M. (2012). PhD existence v oboru psychologie v České republice a na Slovensku [PhD existence in psychology, Czech Republic and Slovakia]. Olomouc: Filozofická fakulta Univerzity Palackého.

Nicholson, N., \& Arnold, J. (1989a). Graduate entry and adjustment to corporate life. Personnel Review, 18(3), 23-35.

Nicholson, N., \& Arnold, J. (1989b). Graduate experience in a multinational corporation. Personnel Review, 18(4), 3-14.

Onwuegbuzie, A. J., Witcher, A. E., Collins, K. M., Filer, J. D., Wiedmaier, C. D., \& Moore, C.W. (2007). Students' perceptions of characteristics of effective college teachers: A validity study of a teaching evaluation form using a mixed-methods analysis. American Educational Research Journal, 44(1), 113-160.

Pitcher, R., \& Akerlind, G.S. (2009). Post-doctoral researchers' conception of research: A metaphor analysis. International Journal of Researcher Development, 1(2), 160-172.

Pope, C., Zielbad, S., \& Mays, N. (2000). Qualitative research in health care: Analysing qualitative data. British Medical Journal, 320(7227), 114-116.

Recotillet, I. (2007). PhD graduates with post-doctoral qualification in the private sector: Does it pay off? Labour, 21(3), 473-502.

Rogers, C. R. (1951). Client-centred therapy. London: Constable.

Rots, I., Aelterman, A., Vlerick, P., \& Vermeulen, K. (2007). Teacher education, graduates' teaching commitment and entrance into the teaching profession. Teaching and Teacher Education, 23, 543-556. 
Scaffidi, K. A., \& Berman, J. E. (2011). A positive postdoctoral experience is related to quality supervision and career mentoring, collaborations, networking and a nurturing research environment. Higher Education, 62(6), 685-698.

Shafritz, J.M., Koeppe, J.P, \& Soper, E. (1998). The Fact on File Dictionary of Education. New York: Fact on File.

Schnitzerová, E. \& Kuban, V. (1992). Slovníkové repetitórium z psychológie [Terminology overview of psychology]. Košice: UPJŠ.

Simplicio, J. (2012). The university culture. Education, 133(2), 336-339.

Smith, R. L., Maroney, K., Nelson, K. W., Abel, A. L., \& Abel, H. S. (2006). Doctoral programs: Changing high rates of attrition. The Journal of Humanistic Counselling, 45(1), 17.

Stephan, P., \& Ma, J. (2005). The increased frequency and duration of the postdoctorate career stage. The American Economic Review, 95(2), 71-75.

Strauss, A., \& Corbinová, J. (1999). Základy kvalitativního výzkumu [Basics of qualitative research]. Boskovice: Albert.

Super, D. E., Super, C., \& Savickas, M.L. (1996). A life-span, life-space approach to careers. Career choices and developments, 3, 212-178.

Světlík, J. (1996). Marketing školy [School marketing]. Zlín: EKKA.

Šed'ová, K., Švaříček, R., Sedláčková, J., Čejková, I., Šmardová, A., Novotný, P., \& Zounek, J. (2016). Pojetí výuky a profesní identita začínajících vysokoškolských učitelů [The concept of instruction and the professional identity of beginning university teachers]. Studia paedagogica, 21(1), 9-34.

Šturzová, J. (2006). Zamyšlení nad otázkou smyslu univerzitního vzdělání ve společnosti výkonu [Considering the meaning of university education in the achievement society]. Liberec: TU, 41-43.

Švaříček, R., \& Šed'ová, K. et al. (2007). Kvalitativní výzkum v pedagogických vědách [Qualitative investigation in educational sciences]. Praha: Portál.

Tajfel, H. (1982). Social psychology of intergroup relations. Annual Review of Psychology, 33(1), 1-39.

Turner, G., \& McAlpine, L. (2011). Doctoral experience as researcher preparation: activities, passion, status. International Journal for Researcher Development, 2(1), 46-60.

Vekkaila, J., Pyhältö, K., \& Lonka, K. (2013). Experiences of disengagement - A study of doctoral students in the behavioral sciences. International Journal of Doctoral Studies, 8, 61-81.

Weidman, J. (2006). Socialization of students in higher education: Organizational perspectives. The Sage Handbook for Research in Education. London: Sage, 253-262. 
Weidman, J. C., Twale, D. J., \& Stein, E. L. (2001). Socialization of Graduate and Professional Students in Higher Education - A Perilous Passage? ASHE-ERIC Higher Education Report, 28(3).

Weisgram, E. E., Bigler, R. S., \& Liben, L. S. (2010). Gender, values, and occupational interest among, children, adolescents and adults. Child Development, 81(3), 770-796.

White, L. (1949). The Science of Culture: A study of man and civilization. New York: Grove Press.

Wiegerová, A. (Ed.) (2012). Young researchers forum. Fórum mladých výskumníkov. Zborník medzinárodných štúdií prezentujúcich práce mladých výskumníkov. Bratislava: SPN.

Wiegerová, A. (Ed.) (2013). Začínajíci výzkumník [Beginning researcher]. Zlín: UTB.

Wiegerová, A., \& Gavora, P. (2014). Proč se chci stát učitelkou v mateřské škole? [Why do I want to be a preschool teacher?]. Pedagogická orientace, 24(4), 510-534. Woodcock, M. (1979). Team Development Manual, 183-206, Aldershot: Gower Publishing. 


\section{FIGURES AND TABLES}

Fig. 1 Phases of the professional career of a university teacher - an ideal model

Fig. 2 The doctoral student's roles

Fig. 3 Personal decisions and career determinants of a university teacher

Fig. 4 Career trajectory one 108

Fig. 5 Career trajectory two 109

Fig. 6 Career trajectory three 109

Fig. 7 Career trajectory four 110

Table 1 Professional routes of the two groups 98 


\section{AUTHOR INDEX}

A

Abel, A. L. 122

Abel, H. S. 122

Aelterman, A. 22, 121

Åkerlind, G. S. 27, 66, 100-101, 117

Ali, A. 88, 117

Anderson, M. T. 54-55, 117

Armstrong, M. 25, 117

Arnold, J. 21-22, 117, 121

Austin, A. E. 49, 53, 117

\section{B}

Backman, K. 36, 117

Baker, V. L. 88, 118

Bandura, A. 22, 118

Berman, J. E. 81, 122

Bigler, R. S. 18, 123

Bledsoe, M. L. 117

Boudreau, J. W. 25, 121

Brailsford, I. 118

Braun, V. 118

Brooks, I. 61, 118

Brown, C. A. 22, 118, 120

Bruinsma, M. 42, 118

Buford, B. J. 117
C

Charvát, M. 27, 121

Clarke, V. 118

Collins, K. M. 121

Corbinová, J. 122

$\check{\mathbf{C}}$

Čejková, I. 122

D

Dalton, P. 20, 22, 118

Davis, G. 27, 68, 118

Dawson, N. 81, 118

Detoy, C. J. 22, 118

Dolejš, M. 121

E

Eagly, H. 121

Eccles, J. S. 14, 19-20, 118

Elliot, R. 37, 118

Ellis, T. J. 120

F

Filer, J. D. 121

Flešková, M. 60, 118 
Folch, M. T. 89, 91, 94, 118

Fournier, V. 20-22, 118

Fransella, F. 20, 22, 118, 120

G

Gardner, S. K. 27, 118

Gavora, P. 12, 42, 119, 123

Goffman, E. 22, 119

\section{H}

Hackett, R. D. 22, 119

Harkins, S. G. 120

Hausdorf, P. A. 22, 119

Hayes, N. 95, 105, 119

Hebden, J. E. 119

Heitlingerová, A. 17, 119

Honess, T. M. 21, 119

Hopwood, N. 27, 121

Horta, H. 82, 119

Huberman, A. M. 36, 121

Hughes, E. C. 21, 119

\section{I}

Ingram, J. M. 117

Ion, G. 89, 91, 94, 118

\section{J}

Jackson, J. M. 81, 119

Janesick, V. 119

Jansen, E. P. 42, 118

Jaraim, D. 27, 74, 119

Jazvac-Martek, M. 27, 121

Jefferson, G. 36, 119

Ježek, S. 77, 120

K

Kahl, D.H. 27, 74, 119

Kato, K. 84, 114, 119

Katzenbach, J. R. 56, 119
Keenan, A. 21, 119

Kelchtermans, G. 61, 120

Kelly, G. A. 14, 20-22, 105, 120

Kern, H. 120

Kirkpatrick Johnson, M. 17

Koeppe, J.P. 41, 122

Kohun, F. 88, 117

Kolařík M. 121

Kosová, B. 12, 42, 120

Kubáni, V. 60

Kundrát J. 121

Kyngäs, H. A. 36, 117

L

Lapierre, L. M. 22, 119

Lappalainen, M. 84, 114, 121

Latané, B. 80, 120

Latham, G. 41, 120

Leitner, L. M. 22, 120

Levy, Y. 120

Liben, L. S. 18, 123

Linn, M. C. 121

Lonka, K. 27, 122

Lorden, J. F. 81, 114, 120

Louis, M. R. 21, 120

Lukášová, H. 42, 120

M

Ma, J. 81, 122

Mabey, C. 120

Mareš, J. 12-13, 22, 27, 40, 47, 77, 81, 120

Maroney, K. 122

Matalon, S. 81, 114, 120

Mays, N. 121

McAlpine, L. 27, 121-122

McDaniels, M. 49, 117

Mehl, C. 120

Melin, G. 27, 121

Miles, M. B. 36, 121 
Milkovich, G. T. 25, 121

Miller, D. I. 19, 121

Moore, C. W. 121

Mortimer, J. T. 17, 120

Murtonen, M. 84, 114, 121

\section{$\mathbf{N}$}

Nelson, K. W. 122

Neusar, A. 13, 27, 48, 50, 121

Newton, T. J. 21, 119

Nicholson, N. 21-22, 117, 121

Nolz, H. 120

Novotný, P. 122

$\mathbf{0}$

Onwuegbuzie, A. J. 117, 121

\section{$\mathbf{P}$}

Paine, R. 20-22, 118

Peter, M. 120

Pifer, M. J. 88, 118

Pitcher, R. 66, 121

Pope, C. 36, 121

Pyhältö, K. 27, 122

\section{$\mathbf{R}$}

Recotillet, I. 81, 121

Rogers, C. R. 79, 121

Rosli, R. 117

Rots, I. 22, 121

\section{S}

Saldaña, J. 36, 121

Savickas, M. L. 22-23, 107, 122

Scaffidi, K. A. 81, 122

Schnitzerová, E. 60, 122

Sedláčková, J. 122

Shafritz, J. M. 41, 122

Simplicio, J. 92-93, 122
Smetáčková I. 121

Smith, D. K. 56, 119

Smith, R. L. 122

Soper, E. 41, 122

Stein, E. L. 51, 123

Stephan, P. 81, 122

Strauss, A. 37, 122

Super, C. 122

Super, D. E. 22-23, 122

Světlík, J. 71, 122

Szarzyńska, M. 121

$\check{\mathbf{S}}$

Šed'ová, K. 13, 27, 38, 122

Šmardová, A. 122

Šturzová, J. 42, 122

Švaříček, R. 38, 122

T

Tajfel, H. 85, 122

Timulak, L. 37, 118

Trnková, Z. 17, 119

Turner, G. 27, 122

Twale, D. J. 51, 123

V

Vandenberghe, R. 61, 120

Vekkaila, J. 27, 122

Vermeulen, K. 22, 121

Vlerick, P. 22, 121

\section{W}

Weidman, J. 51, 85, 122-123

Weisgram, E. E. 18, 123

White, L. 89, 123

Wiedmaier, C. D. 121

Wiegerová, A. 13, 42, 119, 123

Williams, K. 120

Wintersperger, R. 120 
Witcher, A. E. 121

Woodcock, M. 57, 123

Z

Zielbad, S. 121

Zounek, J. 122 


\section{SUBJECT INDEX}

A

academic community $47,51,102-103$, 107, 109

academic potentials 106-107

accredited programmes 96

adaptation $14,23-24,74,77,80$,

82-83, 85, 89-91, 95, 114

administrator $49,59,61,83,91$

anticipation 21

associate professorship 96-98

C

career $11,13-15,17-26,28,33-34$,

$39,42,45,48,60-61,72,74,76,79$,

90-91, 95-96, 98-100, 102-103,

105-111, 113-115, 117-118, 120,

122,124

determinants 105-106, 124

management 25

plans $25,48,95,115$

trajectory 108-110, 124

conferences 51, 63-64, 67, 93,

106-107, 115

constructive revision 21-22

Czech universities $11,13,15,42,53$,

$63,65,67,76-77,81,83-84,114$

\section{D}

data analysis $36-38,121$

disconfirmation 21

dissertation 16, 29-30, 32-34, 37, $43-44,56,65-69,71-77,83$

doctoral programme $16,30-33,37$, 39-50, 52, 54, 57-59, 66-67, 80, 92, $108,110,113$

doctoral study $37,77,79,84,118$

\section{F}

family $14-15,17-18,31-32,41-42$, $45-46,60,62-63,65,73-75,77$, 105-108, 110-111, 113

full-time programme $16,30,44,48$, 58-59, 72

I

identification $34,51,63,77,85-89$, 91-92

IGA 103

integration 37, 49, 51, 63-65, 77, 106

internalisation 63

Interview 34 
methodology $11,14,27,30-31,39,50$, $66,83,85,103$

motivation $17,25,37,41-42,45-47$, $60,73-74,77,95,98,107,118,120$

\section{$\mathbf{0}$}

occupational career $18-19,95,108$, 110-111

occupational potentials $106-107$

\section{$\mathbf{P}$}

participant $34-35,42-43,56-57,61$, $66-67,70,75,83,96,105$

part-time programme $16,43,49$,

58-59, 65, 72, 109

personal career 17

personal constructs $14,19-20,22,39$,

$42-43,65,85,95,108,110,118$

personal potentials 105

personal satisfaction 14, 105, 107

postdoc 29-30,81-82, 114, 118, 121

preschools 85

primary schools 33

professional career 14, 17-25, 33-34,

$72,79,107-110,124$

project $30-31,33,43-44,56,59-60$,

65-69, 72, 82, 84-85, 91, 102-103

\section{$\mathbf{R}$}

researcher $31,34-38,41-42,49$,

$54-57,59,61-62,66-67,80-83$,

85-87, 92, 99, 101-104, 114-115,

$117,119,121-123$

S

science $19,40,51,60,66-67,82,103$,

$114,120-121,123$ secondary schools $31,52,76,80,85$,

99,110

self-confidence 65,74

self-efficacy 22-23, 43, 118

self-esteem $65,74,99$

self-perception 85

socialisation 12, 51, 56, 59, 61, 89, 106

social isolation $88,93-94$

social potentials 106

social roles 49,86

stability 74, 89

supervising 24, 68-69, 86, 118-119

supervisor $16,23,30-33,37,43,54$,

56-57, 62, 65-66, 68-70, 73-75, 77,

85,110

symposia $106-107$

\section{T}

Transcription 35

The Czech Science Foundation 66-67, 103

U

university $11-12,14-16,19,23-24$, 27-35, 37, 39-45, 47-55, 58-64, 67-68, 70-72, 75-77, 79-86, 88-97, 99-111, 113-115, 117-122, 124, 132-133

university culture 77, 89-92, 106, 122 university teachers $11-12,15-16,19$, 23-24, 27-29, 48-51, 54, 63-64, 71, $75,77,81,83-84,86,100,103,105$, $107,109,113-115,121-122$

Y

young researcher 66-67, 81, 103, 114-115 

Tomas Bata University in Zlín

Faculty of Humanities

Faculty Humanities/Pedagogy Series

THE CAREERS OF YOUNG CZECH UNIVERSITY TEACHERS IN THE FIELD OF PEDAGOGY

(C) Adriana Wiegerová, 2021

Scientific Editor: Peter Gavora

Reviewers: Beáta Kosová, Jiří Mareš, Eliška Walterová

English Editing: Gregory Jason Bell

Publishing Editor: Pavel Holík

Cover Design: Tomas Bata University in Zlín

Electronic version

$1^{\text {st }}$ edition, Zlín 2021

Tomas Bata University in Zlín, 2021

DOI: https://doi.org/10.7441/978-80-7454-988-5

ISBN 978-80-7454-988-5 


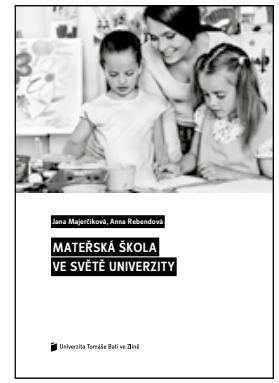

Majerčíková Jana, Rebendová Anna

MATEŘSKÁ ŠKOLA VE SVĚTĚ UNIVERZITY

[Preschool in the University Environment]

Zlín: Tomas Bata University in Zlín, Faculty of Humanities, 2016.

150 p. ISBN 978-80-7454-630-3.

The publication is a single case study of a preschool facility, namely a university nursery. Supported by a rich empirical material the authors offer a description and analysis of the situation in the aforementioned facility. They learn functioning of the observed facility is quite context-conditioned in relation to the specific environment of the university.

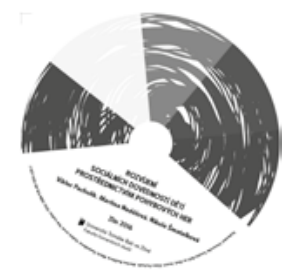

Pacholík Viktor, Nedělová Martina, Šmatelková Nikola ROZVÍJENÍ SOCIÁLNÍCH DOVEDNOSTÍ DĚTÍ PROSTŘEDNICTVÍM POHYBOVÝCH HER

[Developing social skills in children through physical games]

Zlín: Tomas Bata University in Zlín, Faculty of Humanities, 2016. ISBN 978-80-7454-629-7.

The publication provides an excursion into the issue of development of social skills in children in the conditions of a nursery school. The second part focuses on the process and results of a research aimed at determining the effect of an intervention programme of physical activities that develop social skills in children in a nursery. The publication includes a collection of physical games and activities for social skills development in preschool children.

For more information go to: www.nakladatelstvi.utb.cz 






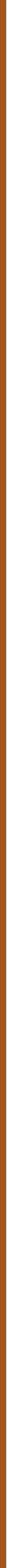

